THE UNIV FESITY OF ORIABOLA

GRADUATE COULBGE

THE PREPARATION OF ALDIMINES TEROOGE

TEE STEPEBN REACTION

\author{
A DISSERTATION \\ SUBMITTED TC TEB GRADUATE FACULTY \\ in partial fulfillment of the requirements for the \\ degree of \\ DOCTOR OF PHILOSOPEY
}

BY

TOAMT LYLE TOLBERT

Korman, Oklahoma

1958 
THE PREPARATION OF AIDIMINES THROOGB

THE STEPHEN REACTION

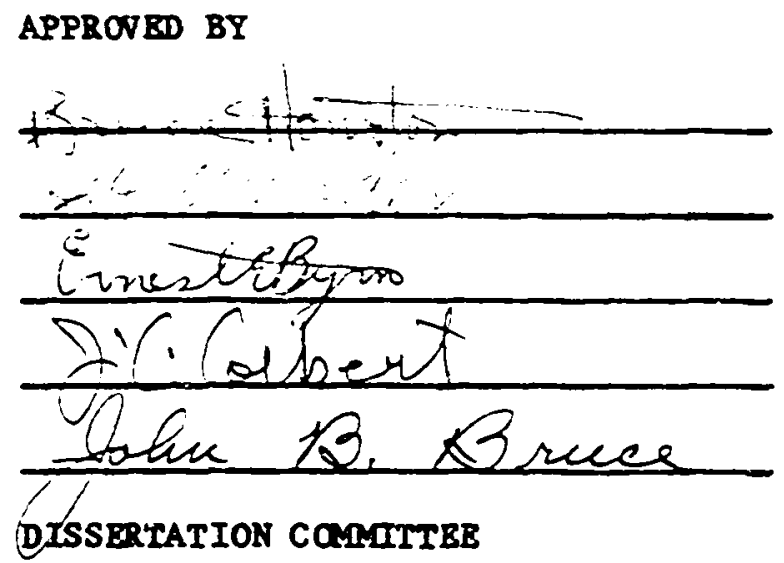




\section{ACXNOWLEDEYENT}

The author wishes to acknowledge appreciat1on to Dr. P. L. Pickard for the suggestion of this problem, and to express his gratitude to Dr. Bruce Houston, under whom this work was carried out, for his thoughtful guidance and consideration and the lesge degree of freedom which he granted.

His sincere appreciation is extended to Phillips Petroleum Company whose grants made this work possible.

Be is grateful to the Faculty and staff of the Departwent of Chemistry for their confidence, their assistance, and their friendship. 
TABLE OF CONTENTS

Page

LIST OF TABLES.............................. v

IIST OF IILUSTRATIONS....................... vi

Chapter

I. INTRODUCTION............................. 1

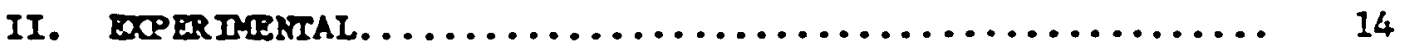

III. RELATED EXPERIMENTAL.................... 56

IV. DISCUSSIOA OR RESULTS...................... 60

v. $\operatorname{sum}$

BIBLICCRAPIY $\ldots \ldots \ldots \ldots \ldots \ldots \ldots \ldots \ldots \ldots \ldots \ldots \ldots \ldots \ldots \ldots \ldots$ 


\section{LIST OF TABLES}

$\begin{array}{ll}\text { Table Page } & \text { Pag }\end{array}$

I. Aldehyder Prepared by the Stephen Reaction........... 11

II. Comparison of Agents for Aldimine Conplex Decomposition. 23

III. Physical Constants of Prepared Aldimines............ 44

Iv. Derivatives of Propared Aldimines................ 46

v. Comparison of Reported Aldimine Physical Constants...... 67

VI. Yields of Aldimine Intermediates, Aldimines, and

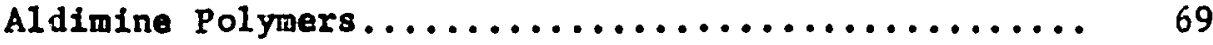




\section{LIST OF ILLUSTRATIONS}

Figure

Page

I. Comparison of Infra-red Absorption Spectra of Benzaldimine and Its Polymers................. 30

II. Spectrum I - Infra-red Absorption Spectrum of Benzaldimine.......................... 48

III. Spectrum II - Infra-red Absorption Spectrum of o-Tolualdimine........................... 49

IV. Spectrum III - Infra-red Absorption Spectrum of p-Tolualdimine........................... 50

V. Spectrum IV - Infra-red Absorption Spectrum of o-Chlorobenzaldimine....................... 51

VI. Spectrum V - Infra-red Absorption Spectrum of

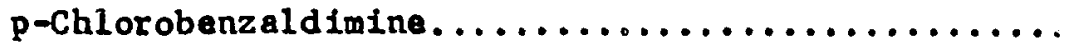

VII. Spectrum VI - Infra-red Absorption Spectrum of

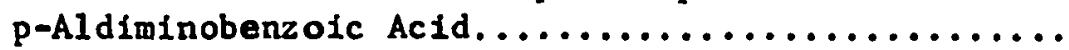

VIII. Spectrum VII - Infra-red Absuiption Spectrum of $\alpha$-Naphthyl acetaldimine....................

IX. Spectrum VIII - Infra-red Absorption Spectrum of o-Trichloromethylbenzaldimine. 


\title{
THE PREPABATION OF ALDIMINES TKROUGH
}

THE STEPHEN REACTION

\section{CHAPTER I}

\section{INTRODUCTION}

\begin{abstract}
An imine can bast be described zs an organic compound which contains a double bonded nitrogen atom attached to a carbon atom; the hydrogen of the imine nitrogen may or may not be replaced. The unsubstituted secondary imines (ketimines) have been very thoroughly studied, and a considerable number of substituted aldimines (primary or terminal Inines) and ketimines have been prepared and characterized. The ungubstituted aldialines, however, are a group of compounds which are so reactive and difficult to obtain pure that they have remalned relatively untouched. This lack of attention 19 not due to unimportance or rarity, for these imines are intermediates in some of organic chemistry's well known reactions, but simply due to difficulties in isolation and purification from the mixtures in which thay are formed. Using as a basis of analogy the resctions of ketimines, it
\end{abstract} should be possible to characterize aldimines by the ease with which they are hydrolysed to the aldeinde; by their basic character as shown by the formation of salts; by the replacement of hydrogen to form N-substituted derivatives, and by their unsaturation as shown by their 
hydroyentition to amines. Support of thls supposition comen from the reported propert lee of the ceralnal imines which have been prepared. Unforeunately, this evldence is somerhat weak, ince only four unsubecituted aldiwines are reported and even these have been only partially characterized.

The long but eparse hlecory of these compounds begins in 1840 with the report of 8 . Itting (1) of the preparation of ealicylaldimine as a part of a metal complex, which would today ts termed a chelate. Since that time a great deal of research has been done on this type of complex, but the aldiminas, se such, have never been isolated.

A. Reychler (2) obtalned a compound which he believed to be acetuldinine in 1884 by the dehydration of an $\alpha$-hydroxy ethylamineallver nitrate cumplex. A trimer of this compound was reportedly obtained by $A$. Delepine (3) in 1889 by reacting the appropriate aldehyde with amonia and dehydrating - room temperature and aspirator pressure. Although a stable, isolated imine was not obtalned, the picrate derivative was reported. H. H. Strain (4) in 1932 was successful in obtaining this trimer by a similar method and claimed tc have isolated the monomer by dry distiliation of the trimer and chilling the vapora. The reactions proving the monomer, however, were chiefly those of an aldehyde. The hydrochloride of benzaldimine was prepazed in 1896 by M. Busch (5). Th18 was accomplished by the reaction of hydrobenzamide, ethanol, and hydrogen chloride to give the imine hydrochloride and ethyl benzacetal. The reactions reportec for the salt are those to be expected from an imine hydrochloride. This salt was again reported in 1925 by V. Grignard and R. Bscourrou (6). An attempt to lsolate benzald- 
Imine formed from the catulytic hydrogenation of the nitrile had been unsuccessful due to the Imine's Instability, but they did report the hydrochloride of the imine. However, tho physical constants differed markedly from t.hose reported by Busch. Some physical constants had been obtained for the unstable inine itself, and the work was reported again by Escourrou (7) in 1929. H. H. Strain (8), in 1930, working with liquid ammonia in an attempt to prepare amino bases analogous to those of water, obtained hydrobenzamide from the reaction of benzaldehyde and liquid ammonia; this reacted further with ammonia to give a crystal1izable oil. This substance was believed to be benzaldimine; however, some of the reactions which Strain reports are unlike those expected from an imine.

Phenylacetaldimine had been prepared in the previously mentioned hydrogenations carried out by Grtgnard and Bscourrou $(6,7)$. This imine proved to be relatively stable and a fairly complete set of physical constants was determined.

By use of Willstäter's platinum black in anhydrous ethanol, B. D. Kohler and N. L. Drake (9) in 1923 were successful in reducing the corresponding nitro compound to diphenylacetaldimine. This compound proved to to a solid, and although it was quite reactive, some physical constants were determined and derivatives prepared.

In the most recent reported work on aldimines the hydrochloride of $\alpha$-methoxy acetaldimine was prepared by reaction of ethanol, acetonitrile, dichloroethane, and hydrogen chloride. The report was made by A. I. Gravin (10) in 1943.

It is surprising that, in the 118 years of active organic 
synthesis since the first report of an aldimine type compound, these substances whose molecular form is well known among organic chemists have not been prepared and characterized. Such a problem 18 challenging and is particularly interesting when one has a background in ketimine chemistry; for this reason the preparation and characterization of aldimines were chosen as the subjects of this dissertation.

Of the three methods of approach to the synthesis which seemed most feasible, hydrogenation of nitriles, modification of an aldehyde synthesis of the Gattermann type, or modification of the Stephen aldehyde synthesis, the last scemed best. The choice was made due to the large amount of work which has been done using the reaction for aldehyde preparation, thus making data on yields, stability of the intermediates, etc., plentiful, and due to the ease of handling to which the reaction seemed to lend itself.

The Stephen reaction can be said to consist of three steps: preparation of anhydrous stannous halide, use of this salt in reduction and complex formation with an appropriate nitrile, and hydrolysis of this complex to the aldohyde. The reaction can be generalized and written:

$$
\mathrm{RCEN}+\mathrm{SnX} 2 \text { dTy } \mathrm{HX}
$$

Alchough there has been controversy over yields and relative value of this reaction, the yields are good except in certain cases of strong steric and/or Inductive effects, and the method 1s, generally speaking, reliable.

Modification of this reaction to produce aldimines rather than aldehydes would require only a nonaqueous rather than aqueous 
decomposition of the etable aldinine hydrohalide-ucennic belide Intermediate. Such a decomposition would leave the inline group incact and le then would be only a problem of leulacion and purffication. Since the Inlitial preparation of the Interwediate da all loportant to the success of the later stepe, as much as paselble should be known about complex formation in the Stophen reaction. For this reason and In order to get an Idea of the applicability and breadth of the reactIon, the work of Stephen and later workers was reviowed carefully. In 1925 Henry Stephen (11) reported his now method of aldehyde preparation. The method was to convert a nitrile into an aldehyde by the addition of an ether solution of the nitrile to a solution of 8 tannous chloride in ether saturated with hydrogen chloride. The nitrile, combining with a molecule of hydrogen chloride, forms an imido chloride which is then reduced to the Imine by the stannous chloride. The imine hydrochloride, formed immediately, ylelds aldehyde on hydro$1 y 818$.

$$
\begin{aligned}
& \mathrm{RCN}+\mathrm{HCl} \longrightarrow \mathrm{RC}(\mathrm{Cl})=\mathrm{NH} \\
& \mathrm{RC}(\mathrm{Cl})=\mathrm{NH}+\mathrm{SnCl}_{2}+2 \mathrm{BCl} \longrightarrow \mathrm{RCH}=\mathrm{NH} \cdot \mathrm{HCl}+\mathrm{SnCl}_{4} \\
& \mathrm{RCH}{ }^{2} \mathrm{NH} \cdot \mathrm{HCl}+\mathrm{H}_{2} \mathrm{O} \longrightarrow \mathrm{RCHO}+\mathrm{NH}_{4} \mathrm{Cl}
\end{aligned}
$$

Stephen reported that, upon reduction of the nitrile, the resulting aldimine precipitated as an aldimine hydrochloride-stannic chloride complex of the form: ( $\left.\mathrm{RCH} \mathrm{H}^{-\mathrm{NH}} \cdot \mathrm{HCl}_{2}\right)_{2} \mathrm{SnCl}_{4}$. The originai report implied that the yields of aldehyde in most cases were very nearly quantitative, but gave few actual yields. Subsequent studies of the method have shown that in certain cases quantitative yields are obtained, but, that in many cases, the yields are considerably less than one would expect 
from stephan' report.

In tho earlier work unlat this reaction, the precipitation of the oldimine elannichlorlde wee taken ea soceure of completenese of the reaction. Lleber (12), however, has dhown that, by varying the condlisons of the reaction, at leaet two different coaplexes can be oblesined, one of which 1s ether wuble. It hes been further shown by Knight and zook (13) that the precipitate obtalned aay not be the pure aldielne cooplex as was previouly supposed, but rather a mixture of the cooplex and the products of olde reaction between the imine and nitrile. This reaction can be postulated as occurring in three stepe: reaction of the lasne with two euccessive molecules of nitrile, and, If wacer is present, reaction with two molecules of water.

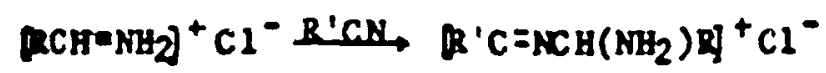

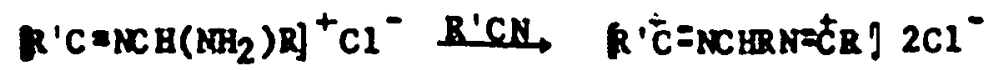

$\left[R^{\prime} t=N \mathrm{CHRN} t_{R^{\prime}}^{\prime}\right] 2 \mathrm{Cl}^{-} \stackrel{2 \mathrm{H}_{2} \mathrm{O}}{\longrightarrow}\left(R^{\prime} \mathrm{CONH}_{2}\right) \mathrm{CHR}+2 \mathrm{HCl}$

Since yields are often calculated from the amount of precipitated complex it is not surprising that variations in yfeld have been reported.

In a ctudy of the kinetics of this reaction, Turner (14) has shown that the rate (another controversial point) of the reaction depends on the concentrations of all three reactancs, nicrile, atannous chloride, and hydrogen chloride. It was shown that precipitation of the aldimine stannichloride is the accelerating factor and often the factor driving the reaction to completion. Removing the imine from the reaction zone also serves to hinder the secondary reaction mentioned above. Turner was also able to how some surprising effects on reaction rate by 
substitution on an aromatic nucleus. This work tends to support the first step in a mechanism proposed by Meorwein (15) which was the formation of aitrilium salt from the nitrile and chlorostannous acid:

$$
\mathrm{R}-\mathrm{CN}+\mathrm{H}_{2} \mathrm{SnCl}_{4} \longrightarrow[\mathrm{R}-\mathrm{C} \equiv \mathrm{NH}]^{+} \mathrm{HSnCl}_{4}
$$

Yields obtalned from the Stephen reaction vary widely, depending on the structure of the nitrile used. Acetonitrile and n-propionitrile give poor yields, however, the yleld from normal alfo phatic nitriles increases markedly with chain length. When unsaturation is introduced into the chain of a phenyl substituted aliphatic nitrile, the yield falls off sharply and continues to decrease with increase in the number of double bonds in the chain. As an example, $\mathrm{C}_{6} \mathrm{H}_{5} \mathrm{CH}=\mathrm{CHCN}$, $\mathrm{C}_{6} \mathrm{H}_{5} \mathrm{CH}=\mathrm{CHCH}=\mathrm{CHCN}$, and $\mathrm{C}_{6} \mathrm{H}_{5} \mathrm{CH}=\mathrm{CHCH}=\mathrm{CHCH}=\mathrm{CHCN}$ give yields of $40 \%, 10 \%$, and a trace respectively. On the other hand, an aldehyde can not be obtained by this method from the unsubstituted aliphatic $\alpha, \beta$ unsatwrated nitrile, 2 nonenoic nitrile. Good to excellent yields of aldehyde are obtained from most aromatic nitriles. Bxceptions in which the yield of an aromatic aldehyde is low can not be explained entirely by steric or inductive effects but seem to be caused by a combination of the two. Relatively few heterocyclic aldehydes have been prepared by the Stephen method; the yields of those which have been prepared by this method, however, are generally good. In some cases modification of the reaction to better fit the propertias of the product has lod to successful preparation of difficultly prepared aldehydes. Modifications of the Stephen method have bean tried by a number of workers. Wittig and Hartman (16) obtained much nigher yields in certain cases by the use of stannous bromide and hydrogen bromide. 
In the instance of the unsaturated cospounds mentioned above, the yield of $\mathrm{C}_{6} \mathrm{~B}_{5} \mathrm{CH}=\mathrm{CHCN}$ increased $25 \%$ ard the yield of $\mathrm{C}_{6} \mathrm{H}_{5} \mathrm{CB}=\mathrm{CBCB}=\mathrm{CHCN}$ increasad $40 \%$ with this variation. Slotta and Kether (17) were also successful in modifying the Stephen procedure, employing stannous chloride preparations containing 1.4 to $1.5 \%$ water. They had observed that absolutely anhydrous stannous chloride did not dissolve in hydrogen chloride saturated ether, while a trace of water made it completely soluble; yields of $80 \%$ to $90 \%$ aldehyde wex obtained.

Excess hydrogen chloride and a temperature elevation of $30-40^{\circ} \mathrm{C}$ above room temperature increased yields in certain cases and leads to an increased reaction rate in all cases. No correlation has been found between the solvent used, the yield obtained, and the type nitrile, but, in preparing certein aldehydes, dioxane (18) has been used to a greater advantage. Stephen (19), himself, has recently eusgested the use of ethyl formate or ethyl acetate as a solvent to obtain slightly improved ylelds. The increased ylelds in these solvents may be due only to the effect of the higher reflux temperature of the solvent. Wittig and Hartmann (16) did scme preliminary work on the effect of replacing stannois chloride with chromous, vanadous, or titanous chloride; all were found ineffective. A modification which makes little change in yield but which is important for a few studies was developed by Turner (14). Desiring to study the kinetics of the Stephen reaction, he wished to accomplish the reduction of the nitrile in such a way that the aldimine stannichloride would not precipitate or, at least, wouju be slow in precipitating and, more important, he wanted the system to be homogeneous before nicrile addition. Both 
aime were achleved when the stannous chloride-hydrogen chloride seturated ether reduction mixture was replaced by mixcure of stannous chloride dihydrate, ether and acetyl chloride.

Table I gives a partial list of aldehydee prepared by the Stephen machod.

Having accepted the challenge of the preparation and characterization of unsubetituted aldimines and with an approach to the synthesis in mind, it was felt that the problem would best be solved in three steps. Inftially a method of preparation and isolation would have to be developed, the compounds then would be characterized as completely as possible by chemical and instrumental means, and finally, a comparison of steric and inductive effects in the new imines would be made. Tha results of this work are described and discussed in the following chapters. 
TABLE I

ALDEMTDES WHICH HAVE BESN PREPARED BY THE STEPHEN REACTION

\begin{tabular}{|c|c|c|}
\hline Allphatics & Yield & Reforence \\
\hline Acetaldehyde & $30 \%$ & 14 \\
\hline n-Propanal & $23 \%$ & 14 \\
\hline n-Butanal & $53 \%$ & 14 \\
\hline n-Pentaral & $61 \%$ & 14 \\
\hline 8-Butanal & $25 \%$ & 14 \\
\hline 2,2 Dimathyl propanal & 227 & 14 \\
\hline$\alpha\left(\beta^{\prime}\right.$-Phenoxyethyl) valeraldehyde & $38 \%$ & 20 \\
\hline n-Octanal & quant.* & 11 \\
\hline n-Dodecenal & $88 \%$ & 12,13 \\
\hline n-Tetradecanal & quant.* & 11 \\
\hline n-Haxaducenal & quant.* & 11 \\
\hline n-Octadecanal & quant .* & 11 \\
\hline Is ocapral dehyde & $31 \%$ & 21 \\
\hline$\beta$-Hydroxypropional & 0 & 21 \\
\hline$r$-Phenoxy $\alpha$-methylbutyraldehyde & $46,51 \%$ & 22,23 \\
\hline$r$-Phthalimido $\alpha$-methylburyraldehyde & $54 \%$ & 23 \\
\hline r -Phthalimido-butyraldehyde & $74 \%$ & 24 \\
\hline$r$-Phenoxybutyraldehyde & $79 \%$ & 25 \\
\hline 5-Phenyl pentadienal & $50 \%$ & 16 \\
\hline Cinnanyl seldekyde & $65,40 \%$ & $16,26,27$ \\
\hline
\end{tabular}


TABLE I (Continued)

Phonylacetaldehyde

$\beta$-Phenylpropionaldehyde

P Chlorophenylacetaldehyde

p -Tolylacetaldehyde

$\beta$-Phenylpropionsl

Cinnamylideneacetaldehyde

Malonaldehyde tetraethylacetal quant.*, $33 \% \quad 11,21$

quant .*

11

quant .*

11

quant.*

11

quant.*

11

$10,50 \%$

16,26

$35 \%$

28

\section{Aromatics}

$\alpha$-Naphthaldehyde

$\beta$-Naphthaldehyde

2,7-Naphthal ened Icarboxal dehyde

Benzaldehyde

o-Chlorobenzal dehyde

m-Chl orobenzal dehyde

p.Chlorobenzaldehyde

o-Tolualdehyde

m-Tolualdehyde

p-Tolualdehyde

p-Methoxybenzaldehyde

m-Trifluoromethy1benzaldehyde

p-Trifluoromethylbenzaldehyde

p-Bromobenzaldehyde

p-Iodobenzaldehyde
Yield

Reference

quant.*, 20,7\% $19,21,24$

$91 \%$

21,29

$24.3 \%$

30

$97 \%$

$11,16,21,27$

quant.*

11

$53 \%$

31

quant .*

11

quant.*, $9 \%$

$11,21,24$

$50 \%$

31

quant . $*, 30,70 \% 11,19,21$

$15 \%$

19

0

32 .

$26 \%$

33

$62 \%$

31

$56,70 \%$

31 
TABLE I (Continued)

\begin{tabular}{|c|c|c|}
\hline 3-Fluoro-4-methoxybenzaldGhyde & $63 \%$ & 34 \\
\hline 3-Acetyl-6-methoxybenzal dehyde & $39 \%$ & 35 \\
\hline $3,4,5$-Trimethoxybenzal dehyde & quant. *, 10-20\% & 11,36 \\
\hline 3-Caxbomethoxybonzal dehyde & 847 & 17 \\
\hline 4-Carbomethoxybenzal dehyde & $90 \%$ & 17 \\
\hline 3-Carbethoxybenzaldehyde & $86 \%$ & 36 \\
\hline 4-Carbethoxybenzaldehyde & $86 \%$ & 17 \\
\hline 3- $\beta$-Chlorocarbethoxybenzal dehyde & $74 \%$ & 17 \\
\hline 4- $\beta$-Chlorocarbethoxybenzal dehyde & $75 \%$ & 17 \\
\hline $\begin{array}{c}\text { 4-(3',5'-Difodu-4'-methoxyphenoxy) } \\
\text { benzaldehyde }\end{array}$ & $55 \%$ & 37 \\
\hline 3,5-Dilodo-4-(2'-methoxyphenoxy) benzal dehyde & $55 \%$ & 38 \\
\hline 3,5-D11odo-4-(3'-methoxyphenoxy) benzaldehyde & $75 \%$ & 39 \\
\hline $\begin{array}{c}\text { 3,5-Dich1oro-4-(4'-methoxyphenoxy) } \\
\text { benzal dehyde }\end{array}$ & $75 \%$ & 40 \\
\hline $\begin{array}{c}\text { 3,5-Dibromo-4-(4' -methoxyphenoxy) } \\
\text { benzaldehyde }\end{array}$ & $80-85 \%$ & 40 \\
\hline 3,5-Dilodo-4-(4'-methoxyphenoxy) benzaldehyde & $70-100 z$ & 41 \\
\hline $\begin{array}{c}\text { 3,5-Dilodo-4-(3' fluoro-4 '-methoxyphenoxy) } \\
\text { benzal dehyde }\end{array}$ & $68 \%$ & 42 \\
\hline $\begin{array}{c}\text { 3,5-Diiodo-4-( } 3^{\prime}, 5^{\prime}-\text { difluoro } 4^{\prime} \text {-methoxyphenoxy } \\
\text { benzaldehyde }\end{array}$ & y) $72 \%$ & 42 \\
\hline p-Sul famylbenzaldehyde & 0 & 43 \\
\hline p-Methylsul fonylbenzal dehyde & $68 \%$ & 44 \\
\hline p-Phenylsul fonylbenzaldehyde & $82 \%$ & 43 \\
\hline 4-(4'-Methyl phenyl thio) benzaldehyde & 817 & 44 \\
\hline 4-(4'-Ethoxyphenylthio) benzaldehyde & 827 & 44 \\
\hline
\end{tabular}


TABLE I (Continued)

3,5-Dilodo-4-(4'-methoxyphenyl thio) benzaldehyde

$66 \%$

2-Hydroxy-4-wet hoxybenzaldehyde

good

46

4-Hydroxy -2-methoxybenzaldehyde

ริก0d

46

p-Methyl-p'-aldehydo diphenylsulêtde

$81 \%$

44

p-Ethoxy-p'-aldehydo diphenylsulfide

good

44

\begin{tabular}{cll}
\hline Heterocyclics & Yield & Reference \\
\hline $\begin{array}{c}\text { Nicotinaldehyde thiosemicarbazone } \\
\text { 4-Ethoxymethyl-2-hydroxy-6-methylp yridine- } \\
\text { 3-carboxaldehyde thiosemicarbazone }\end{array}$ & $10 \%$ & 45 \\
$\begin{array}{c}\text { 2-Benzyloxazole-4-carboxaldehyde } \\
\text { 4-Methylthiazole-5-carboxaldehyde }\end{array}$ & $88 \%$ & 45 \\
\end{tabular}

*Yield reported by Henry Stephen 


\section{CHAPTER II}

\section{BXPER IMBNTAL}

This chapter is devoted to the preparation of aldimines and their intermediates. The next chapter, Chapter III, w111 deal with the work carried out which is related but not directly connected to imine synthesis.

Preparation of Stannous Chloride. Stannous chloride dihydrate as obtained comercially usually contained several impurities, the principle one being stannic oxy-chloride. These impurities were most conveniently removed and the salt dehydrated to the pure, anhydrous stannous chloride by the method of H. Stephen (49). The dihydrate was treated with twice the molar volume of acetic anhydride and, after the reaction had subsided, the mixture was cooled. This treatment dehydrated the salt and, since the impurities present were soluble in acetic acid, filtration and thorough washing with anhydrous diethyl ether yielded the pure, dry, halide. The resulting salt was white, finely powdered, and slightly hydroscopic.

of the methods tried, the salt seemed to keep best under a slight vacuum and in the dark. It remained unchanged for several months under these conditions. If this precaution was not observed, darkening of the salt occurred within a few days. 
Preparation of Stannous Bromide. The stannous bromide which was used was prepared by a modification of the method of Wittig and Hartman (16). The bromide was prepared in solution by the reaction of metallic tin and aqueous hydrogen bromide. Water was then gradually distilled from the system until only the molten salt remained at a temperature of 400 to $450^{\circ} \mathrm{C}$. The bromide which Wittig and Hartman used was obtained by distilling this mixture at $620^{\circ} \mathrm{C}$ and collecting the bromide distillate. However, since reactants of high purity were used, it was felt that distillation of the molten reaction mixture was unnecessary. The mixture was poured into a porcelain dish and allowed to cool slowly in a desiccator. On cooling, a dense mass of silvergray, very large crystals were obtained; after being powdered these were kept in a sealed bottle and in the dark.

Nitriles. Whenever possible, the nitriles needed were obtained commercially. The nitriles obtalned in this manner were benzonitrile, phenylacetonitrile, diphenyacetonitrile, o-, m-, and p-toluaitrile, p-aminobenzonftrile, $0-$, and p-chlorobenzonitrile, 2-cyanopyridine, $\alpha$-naphthylacetonitrile and $\alpha$-naphthonitrile. Bach of these was purified either by distillation or recrystallization before use.

Freparation of p-Nitrobenzonitrile. This compound was obtained in $90 \%$ yield following the procedure developed by C. S. M11ler (50). The general method was the transamidation of p-nitrobenzoic acid, followed by dehydretion with phosphorous pentachloride.

The compound was also prepared by a modified Sandmeyer reaction. Using the preparation of 2,4 dinitrobenzonitrile by F. R. Storrie (51) as an analogy, the nitrile was prepared using 0.13 moles of potassium 
nickelocyanide, 0.12 moles of nitrous acid, and 0.1 moles of p-nitroaniline in a standard Sandmeyer reaction. The potassium nickelocyanide was prepared by mixing a solution of 35 grams of potassium cyanide in $150 \mathrm{ml}$. of water with a solution of 28.6 grams of nickelous chloride hexahydrate in $50 \mathrm{ml}$. cf water, and sooling the resulting wixture. The yield ebtained after recrystallization from acetone was $70 \%$. Preparation of N-Acetyl p-Aminobenzonitriley This compound was prepared in $97 \%$ yield by treating p-aminobenzonftrile in anhydrous diethyl ether with an excess of acetic anhydride. The product melted at $199-200^{\circ} \mathrm{C}$.

Preparation of $p$-Cyanobenzolc Acld. The method of E. P. Valby and H. J. Lucas (52) was followed with only one modification. The general synthesis was a Sandmeyer reaction involving a cuprous chloridesodium cyanide mixture reacting with diazotized p-aminobenzoic acid. The only change in the procedure was to use, in addition to the theoretical quantity of cuprous chloride, 0.1 mole of cupric sulfate in forming the reactant mixture with sodium cyanide. The result of this variation in procedure is a yleld of $82 \%$ nitrile (m.p. $216^{\circ} \mathrm{C}$ ) rather than the $45 \%$ yield reported. Recrystallization from water resulted in an overall yield of $75 \%$ of product melting at $219^{\circ} \mathrm{C}$. Analysis based on percent nitrogen by the semimicro Dumas method showed: theoretical, 9.52\% N; found $9.65 \% \mathrm{~N}$.

Preparation of p-Cyanobenzaldehyde. Reaction between p-cyanobenzylbromide and the sodium salt of 2-nitropropane resulted in a $67 \%$ yield of this nitrile. The method was developed by H. B. Hass and $M$. I. Bender (53). 
Preparation of Salicylnitrile. The preparation of this nitrile involved the dehydration of salicylaldoxime with acetic anhydride. Following the method of E. Beckmann (54), a $74 \%$ yleld was obtained. An attempt was also made to prepare this compound by the dry distillation of a mixture of salicylamide and phosphorous pentoxide. Less than $3 \%$ of the nitrile was obtained by this method.

Preparation of o- and P-Trichloromethylbenzonitrile. An 85\% yleld of o-trichloromethylbenzonitrile was obtained when dry, gaseous chlorine was bubbled into a mixture of one mole of o-tolunitrile and five grams of phosphorous pentachloride at $180^{\circ} \mathrm{C}$. After 70 hours, the theoretical quantity of chlorine had been taken up, as shown by the increase in weight of the mixture. The flow of gas was stopped and the mixture was vacuum distilled. The nitrile distilled at $146^{\circ} \mathrm{C}$ and $0.15 \mathrm{~mm}$. pressure. Finel purification was by recrystallization from hot, absolute ethanol.

The melting point shown by this nitrile, $96.5^{\circ} \mathrm{C}$, was $1.5^{\circ} \mathrm{C}$ higher than that previously reported for the compound $(55,56)$. Anslysis of the nitrile by the semimicro Dumas method showed a nitrogen content of $6.32 \%$. o-Trichloromethylbenzonitrile contains $6.34 \%$ nitrcgen.

p-Trichloromethylbenzonitrile was prepared by bubbling dry, gaseous chiorine into p-tolunitrile at $180^{\circ} \mathrm{C}$ and under strong 1 ight. The light source was a 200 watt, unfrosted, incandescent light bulb held 0.5 inches from the wall of the reaction vessel. The flow of gas was stopped after 40 hours and the mixture was vacuum distilled. The nitrile distillate, after recrystallization from hot, anhydrous ethanol, 
represented only 117 of the quantity theoretically possible. The nitrile melted at $209^{\circ} \mathrm{C}$. Analysis of the compound by the semimicro Dumas method showed a nitrogen content of 6.39\%. p-Trichloromethylbenzonitrile contains $6.34 \%$ nitrogen. Hydrolysis of the prepared nitrile produced a compound having a neutralization equivalent of 167 ; terephthalic acid, the hydrolysis product of p-trichloromethylbenzonftrile, has a neutralization equivalent of 166.

Preparation of 3-Cyanopyridine. A yleld of $60 \%$ was obtained when this compound way prepized by the dehydzation of nicotinamide with phosphorous pentachloride. The amide was thoroughly mixed with a $30 \%$ molax excess of the chloride and the reaction inftiated by heating the mixture to $50^{\circ} \mathrm{C}$. After the initial reaction had subsided, the temperature of the system was gradually raised to $200^{\circ} \mathrm{C}$ and beld there until nothing else distilled. The mixicure was then cooled and pyridine (three times the molar amount of $\mathrm{PCl}_{5}$ used) was slowly added with stirring. The system was again cooled to room temperature and water (twice the molar amount of $\mathrm{PCl}_{5}$ ) was added slowly. The nitrife was removed frcm the mixture by filtration and was thoroughly washed with water. Pinal purification was by vacuum distillation. The compound melted at $50^{\circ} \mathrm{C}$.

\section{Preparation of the Nitrile-Stannic Halide Complexes. There} axe two general methors by which these complexes can be prepared. The most recent method, developed by Turner (14), gives a homogeneous system which is ideal for kinetlc studies of the complex formation but which is somewhat incomvenient for preparative work. This procedure was discussed in Chapter I. The original method of Stephen (11) is still the 
more widely used and is, for most purposes, the better of the two. In the system producad by the older procedure the complex which is formed is insoluble, and 80 may be isolated. It was often very convenient to Isolate the scable, solid complex, therefore the Stephen procedure was used throughout this studs.

The complex was formed by addition of a nitrile to a mixture of diethyl ether and stannous halide which had been previously saturated with the corresponding hydrogen halide. Conveniently, the ether, salt, and gas formed a liquid complex, so one could be sure of a hydrogon halide saturated system as soon as solid was no longer present in the mixture. At this point the system was composed of a clear, coloriess, upper, ethereal layer and a clear, pale yellow, immiscible, lower layer of stannous complex. The nitrile was added with stirring to this two phese mixture; immediate, though not vigorous, reaction was usually apparent. However, even though some reaction did occur on mixing, initial precipitation required from three to ninety-six hours. Once the initial precipitate had formed, the solid accumulated rapidly and was usually completely precipitated within eighteen hours. There was some evidence thet resaturation of the mixture after several hours with the appropriate hydrogen halide would push the reaction nearer completion than it would have otherwise gone. For this reason 211 of the complex mixtures were resaturated with the halide gas at twelve hour intervals until reaction seemed complete.

All of the complexes prepared were stable, crystalline solids. There was no difficulty in filtering, washing, and drying the precipitates, and no change was apparent when they were stored for long pariods 
of time, if they were dry, under a slight vacuum, and in the dark. Some decomposition of the complexes occurred if they were not complotely dried when stored, or if they were stored in colorless bottles and left in the 11ght.

The amount of solid precipitated in the preparation of many of the complexes was near the theoretical amount of complex. However, several workers in the field have shown that the precipitate which forms may not be pure complex, while others have shown that precipitation is not necessarily a criterion of the extent of the reaction. For these reasons all of the yields reported are based only on the amount of starting nitrile and the amount of purified imine actually obtained. Solvents Used. A variety of solvents were tested for use during the decomposition of the nitrile-gtannic halide complex. Among the characteristics of a solvent ideal for this purpose are that it be non-reactive, readily avallable, easily handled and, most important, that it dissolve imine without dissolving the nitrile comple: or tin salts. The compounds tested were: diethyl sther, pyridine, acetone, dimethyl formamide, ethyl formate, and 1,4 dioxane.

Diethyl ether proved to be the most useful of these and was used exclusively. It was avallable, non-reactive, had a low bolling point, and could be handled with ease. The nitrile-stannic halide complex was insoluble in ether and could be completely freed of the ethereal stannous complex by thorough washing with ether; and yet, when the nitrile complex was decomposed, the imine produced was completely soluble while the residual tin containing products were not. The solvent 
was obtainad as comerclal "anhydrous dlethyl ether" and was not treated before use. In the many cases where the othor was raused, if the reactIon Involved a gas such as ammonia or hydrobiti helide, care was taken to use the reclaimed ether only in a reaction of the type from witich it had come.

Pyridine, as a weak base, acted not only as solvent for the Imine but also as a very mild decomposition reagent of the nitrile complex. Bven with this mild reactivity for the complex, no definite advantage was found in its use.

Acetone proved to be an excellent solvent for imine; some solution of Imine occurred even from unreacted complexes, probably due to the solubility of the complexes in the solvent. This solubility of the reaction 8 alts in acetone, however, prevented its use. Although several attempts were made using it as a solvent, no way was found to adequately control salt as well as imine solucion in acetone.

Dimethyl formamide seemed to be a fairly good solvent for the purpose, but was not used due to its cost and lack of availability. Bthyl formate, a superior solvent when the complex was to be hydrolysed to the aldehyde, was not usable here. This was due to its reactivity with strong bases to give the amide. As an example, when an attempt was made to decompose a complex by treatment with ammonia with ethyl formate as the soivent, the complex was not afiected tut a fine yield of formamide was obtained.

1,4 Dioxane offered no apparent advantages over diethyl ether and was more expensive and less available; consequently it was not used. Mathods of Complex Decomposition. Using the nitrile-stannic 
hal ide complexes of benzaldimine, phonylacetaldimine, diphenylacetaldImine, and p-tolualdimine a variety of decomposition methods were tested In an effort to find one whlch would be general for aldimine preparation. In each case anhydrous diethyl other was used as the solvent. The results of these tests are sumarized in Table IX.

Ammonia did not seem to be a stiong enough base for complete complex decrmposition. In the case of benzaldimine, some reaction with the complex did occur, but the equilibrium was far to the side of the complex. The reagent was useful however when the intermediate was not 18olated from the system, but was decomposed 1mmediately after precipitation. In this case the large excess of hydrogen halide in the system was first removed by reaction with anhydrous ammonia; the complex could then be decomposed with a minimum of reagent.

Triethylamine was the best and most genaral reagent found for the nitrile-stannic halide decomposition. By its usa benzaldimine could be frolated in nearly quantitetive yields and fairly complete decomposition of the other intermediates could be shown in every case tried. In many of these preparations, because of the reactivity of the imine, it was necessary to measuxs the completeness of decomposition on the basis of indirect evidence. In these instances the amount of polymex formed or the amount of aldehyde which could be formed by hydrolysis of either the imine or complex residue mixture was taken as a measure of the extent of the decomposition. The only disadvantage found with the use of triethylamine was that since it was an amine, it reacted very similarly to an imine. Although in some procedures this complicated separation of the two compounds after the Imine was generated, it was not a 
TABLB II

COAPARISON OF AGENTS FOR ALDIMINE COAPLEX DECOAPOSITION

\begin{tabular}{|c|c|c|}
\hline $\begin{array}{l}\text { Agents Used For } \\
\text { Complex Decomposition }\end{array}$ & $\begin{array}{l}\text { Complexes } \\
\text { Tested }\end{array}$ & Resulte \\
\hline Ammonia & $\begin{array}{l}\mathbf{B} \\
\mathbf{P}\end{array}$ & $\begin{array}{l}\text { 3\% yield of imine } \\
\text { only a trace of imine freed from } \\
\text { the complex }\end{array}$ \\
\hline Triethylamine & $\begin{array}{l}\text { B } \\
P \\
d P \\
\text { PT }\end{array}$ & $\begin{array}{l}\text { Near quant. yield } \\
\text { Good yleld of imine polymer } \\
\text { Good yleld of imine polymer } \\
5-10 \% \text { yield of imine }\end{array}$ \\
\hline Tributylamine & $\mathbf{B}$ & $\begin{array}{l}\text { Good yield but azeotrope formed } \\
\text { with the imine } \\
\text { Good yield but azeotrope formed } \\
\text { with the imine }\end{array}$ \\
\hline Sodium Methoxide & B & $\begin{array}{l}\text { Some Imine freed but rasidue } \\
\text { hard to handle }\end{array}$ \\
\hline Sodium Bthoxids & B & Complex decomposition incomplete \\
\hline Pyridine & B & Complex decomposition incomplete \\
\hline Diethylamine & B & Complex decomposition incomplete \\
\hline Bthylenediamine & $\begin{array}{l}\text { P } \\
\text { pT }\end{array}$ & $\begin{array}{l}\text { Good yield of imine polymer } \\
5-10 \% \text { yield of imine }\end{array}$ \\
\hline Dimethyl formamide & B & Complex decomposition incomplete \\
\hline Hydrogen Sulfide & B & Decomposition slow and incomplete \\
\hline Silver Acetate & B & $\begin{array}{l}\text { Good yield and easily handled } \\
\text { residue }\end{array}$ \\
\hline Sodium Acetate & $\begin{array}{l}\mathrm{B} \\
\mathrm{pT}\end{array}$ & $\begin{array}{l}\text { Yield very good } \\
\text { Yield of polymer good }\end{array}$ \\
\hline Sodium Iodide & B & $\begin{array}{l}\text { Decomposition occurs but imine } \\
\text { difficult to isolate }\end{array}$ \\
\hline
\end{tabular}


TABLB II (Continued)

Heat and Vacuum

B

Poor yield

$\mathbf{P}$

No Imine obtained

*Symbols: B - benzaldimine complex

P - phenylacetaldimine complex

dP - diphenylacetaldimine complax

pT - p-tolualdimine complex 
major problem, since separation by distillation was usually relatively easy.

In some ways the use of tributylamkne had definfte advantages over use of the triethyl compound; the reaction was slower and more easily manageable and the salt residue was wore crystalline. However, purification could not be 80 easily accomplished by distillation since this amine bolled $124^{\circ} \mathrm{C}$ higher than triethylamine and, most important, since it formed azeotropes with the two imines uñ whose cowplexes it was tried.

Sodium methoxide reacted vigorously with the stannic complexes and some imine was released, but the residne formed was so difficult to handle that the method showed no obvious advantages. Sodium ethoxide also reacted vigorously, but the imine which was generated was still combined with a tin containing compound. Th1s new imine complex, or compound, was so reactive and impure that the method was abandoned. Diethylamine reacted very vigorousiy with a complex of this type and continued to react until a 5 to 6 times nolar quantity had been added. The reaction was very hot, a flammable gas was given off, and the solid complex Increased in volume by a factor of two to three. Only a trace of Imine was freed.

Bthylenediamine was tried in an attempt to replace the imine In the stannic complex. The ability of this amine to form stable complexes coupled with its basic properties made the compound seem ideal for the purpose. While some Imine was obtained, the greater part of the stannic complex only added etbylenediamine rather than undergoing a replacement reactica with it. A large volume of flammable gas was 
gtven off in this reaction.

Imine could be generated fairly effectively by suspending the complex in rapidly atirred dry ather and bubbling in dry hydrogen sulfide. The primary difficulties her were that the decomposition was slow, requiring resaturation with hydrogen sulfide over severei days, and was likely to be incomplete.

A similar method of attack and a much better one was the use of silver acetate. This salt was readily soluble in dry ether, reacted rapidly, and gave an easily filterable, voluminous residue. The yields of imine were very good, approaching those obtained from the use of triethylamine. Unfortunately, five to 8 ix molar proportions of silver salt per molar amount of complex were required for the reaction. Anhydrous sodium acetate was an effective agent for the decomposition of the tannic complex and gave a decomposition residue which was easily handled. The yields obtained were nearly as good as the ones produced using the triethylamine. However, some agent introduced by this salt seemed to afd polywer formation and 80 made purification by distillation more difficult. The polymers obtained when this salt had been used had a wine-red color not present in those produced from Imine obtained by other methods.

An attempt was made to use sodium lodide in the same way that sodium acetate had been used. The method was extremely unsatisfactory. Aithough complex decomposition occurred, it was not possible to isolate any imine because of the mixture which was formed with it.

Some complex decomposition occurred when the intermediate was suspended in a high boiling liquid, such as mineral oii, undar a pressure 
of one millimeter or less and was heated until something distilled. If heating was slow and the mixture was stirred during heating, some Imine was obtained, but was always impure due to codistillation of tin containing compounds. The method was relatively awkward and slow, and the yields were very low.

Benzalds.mine. This compound was prepared by decomposing a benzonitrile-stannic chloride complex under anhydrous conditions. The complex was formed by saturating an anhydrous diethy! ether solution of stannous chloride with hydrogen chloride and adding benzonitrile. The molax amount of nitrile added was one-third the molar amount of salt used. After 6.5 hours $50 \%$ of the theoretical quantity of the Intermediate had precipitated. It was found that by saturating the system with hydrogen chloride about six hours after addition of the nitrile it was possible to isolate a $90 \%$ yield of the dry, ether washed, complex.

Decomposition of the intermediate by a number of methods was possible. A yield of $70 \%$ or over of imine was isolated when the dry complex was placed in ether and decomposed by triethylamine, tributylamine, silver acetate, sodium acetate, or hydrogen sulfide. When the compiex was not isolated but decomposed immediately in the same system, a yield of $93.9 \%$ was obtained. In this casa the excess hydrogen halide was reacted with ammonia before decomposition of the complex with triethylamine was carried out. The molar amount of triethylamine used was five times that of the nitrile. Since on hydrolysis the dccomposition residue gave positive tests for aldehyde, it may be possible by modifying this procedure to obtain an even higher percent of imine freim 
the reaction.

The physical constants obtained for benzaldimine are shown in Table III and the Infra-red spectrum in Spectrum I. Using these physical constants in the Lorentz-Lorenz formula of molar refraction a deviation of on $1 \% 0.63 \%$ from the value given by the sum of molar refractive equivalents was obtained. The refractive equivalent value for the double bonded nitrogen is not presented in most tables; the value obtained by P. L. Pickard and coworkers (57), 3.129, was used for this calculation. The derivatives of benzaldimine which were prepared are shown in Table IV.

Since the physical constants of the compound differed somewhat from those given by previous workars, a very careful analysis of the product imine was made. Determination of the degree of alkalinity was made by the method of Iddings (58); this Involved nonaqueous potentiometric titration of the imine in glacial acetic acid by perchloric acid in glacial acetic acid. The equivalent weight of the lmine by this method was 105; benzaldimine would show an equivalent weight of 105 . The percent nitrogen in the compound was determined by the semimicro Dumas method. This analysis showed nitrogen content to be 13.48\%; theoretical nitrogen content of benzaldimine is $13.46 \%$.

It had been observed that on long standing or when subjected to excessive heat a benzaldimine sample would become faintly colored and show a change in refractive index. A short but interesting study was made to determine what the change was and how it could be promoted. When the colored substance was isolated it proved to be a sticky, brown polymer-1ike material which formed a glass-1ike substance with further 
heating. On the assumption that this material was a polymer, a comparison of Infra-red spectra was made. The samples compared were purified imine, imine which had baen held at its boiling point at atmospheric pressure for one minute, and imine to which a very tiny particle of free radical former, benzoyl peroxide, had been added at room temperature and which had then been heated and held at its boiling point at atmospheric pressure for one minute. After four hours at room temperature the purified imine was unchanged, the heated imine was still clear but pale brown in color, and the imine treated with both peroxide and heat was clear but dark brown in color. The spectra of the three samples taken at this time were super-imposable except for the four portions of the spectrum which are shown in Figure I. The in these spectral portions seemed to show that the reaction of she two treated samples was of the same type and differed only in degree. These spectra proved nothing, but were perhaps indications of a free radical mechanism of imine polymerixation.

Phenylacetaldimine. Nonaqueous decomposition of a phenylacetonitrile-stannic chloride complex produced a solution of this aldimine. The complex was formed by reacting a diethyi ether solution of stannous chloride saturated with hydrogen chloride with phenylacetonitrile. When the molar amount of nitrile was one-third the molar amount of the salt used, it was possible to isolate $79.8 \%$ of the theoretical amount of the complex. No difficulty was encountered in decomposing this nitrile complex, as shown by hydrolysis of the decomposition residue, but, although many attempts have been made to isolate the imine, none has been obtained in pure form. The presence of the 
FIGURE I

COMPARISON OF INFRA-RED ABSORPTION SPBCTRA OF BENZALDIMINE AND ITS POLYMERS
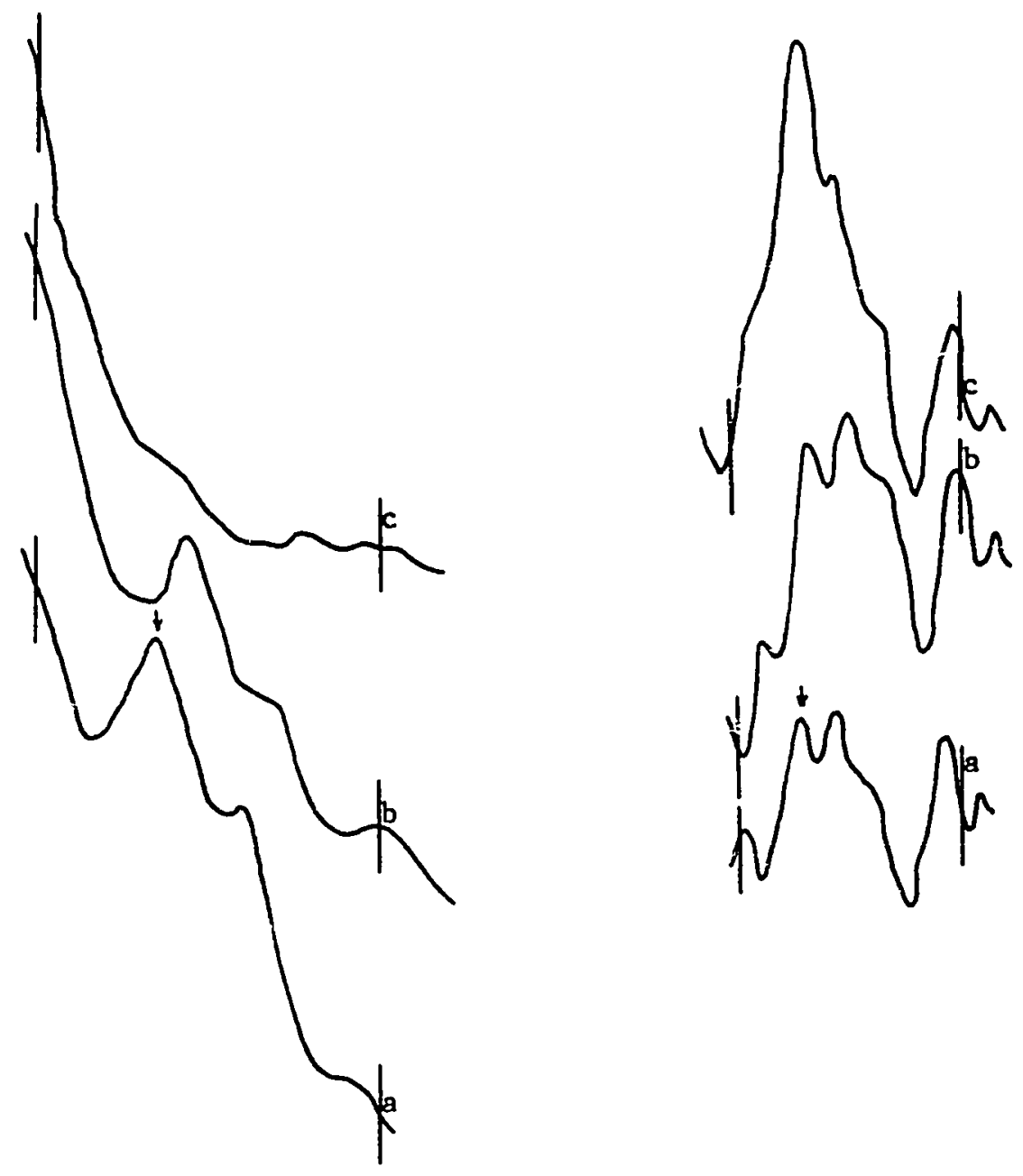

Section 1. Peak at 3.33 , =N-H Stretching vibration

Section 2. Peak at $5.84,-C=N-$ Stretching vibration 


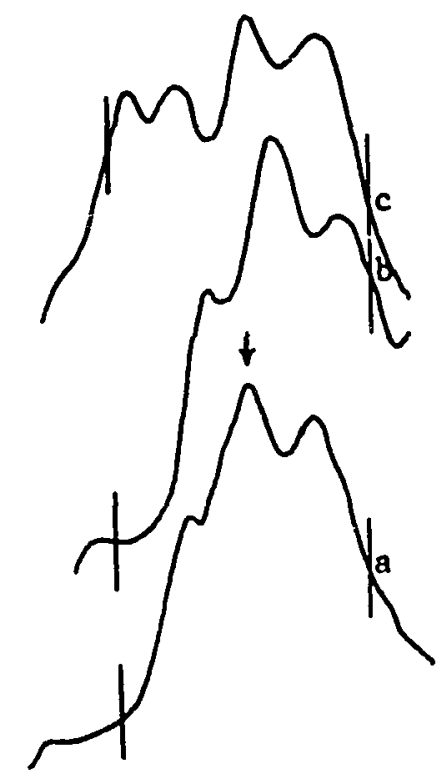

Section 3. Peak at 8.47
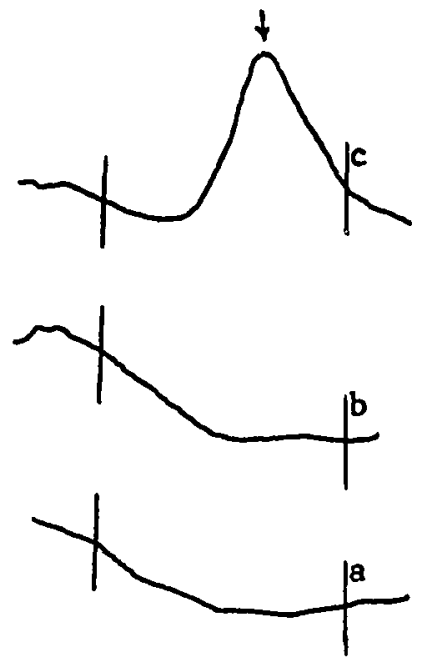

$$
\begin{aligned}
& \text { Secrion 4. Peak at } 11.85 \text {, may } \\
& \text { be the peroxide 0-0 } \\
& \text { stretching vibration }
\end{aligned}
$$

All other portions of the spectra were superimposable. The entire spectrum of benzaldimine is shown in Figure II.

\footnotetext{
a - pure benzaldimine

b - benzaldimine treated with heat

c - benzaldimine treated with free radical contributor and heat
} 
imine in solution has been shown by the preparation of a number of derivatives. These are given In Table IV. However, as soon as the compound was concentrated, it began to polymerlze. It was possible to distill a fraction of the aldimine before it all polymerized, but even this fraction showed evidences of polymer fornation within an hour. The physical constants obtained from this fraction immediately aftor distillation are shown in Table III. Although it is possible that small amounts of impurities were entrained in the collection of the fraction, these constante probably are those of the pure imine. Yield of this compound, if calculated on the welght of polymer obtained, would be $70 \%$ or better.

The ease of polymerization of phenylacetaldimine, even at room temperature, is not surprising. Due to the volatility of tin compounds, even a carefully distilled fraction of the imine might easily have contained a trace of tin salt, an excellent polymerization agent. Another and probably more Important factor is the similarity of atructure between phenylacetaldimine and styrylamine. It seems likely that there would be some equilibrium between the tautomers, expecially since the amine is the conjugated form. Any tendency toward such an equilibrium would explain polymerization of the entire sample.

The polymer which was formed was a translucent, brown, easily fractured, glass-like material which was soluble in many organic solventa. Refluxing the material in an acidifled aqueous medium resulted in a neax quantitative yield of the aldehyde; refluxing in non-aqueous solvents changed the form of the polymer (often to large crystals), but no imine was obtained. 
In an attempt to reduce polymerization a trace of hydroquinone was added before distillation of a phenylacetaldimine mixture. Polymerization was 1 ess rapid than without the hydroquinone, but did occur. However, the form of the polymer which resulted was changed; this polymer was a Jark brown viscous liquid which would not crystallize. Diphenylacetaldimine. The complex from which this compound was obtained was prepared by reaction of an ether solution of stannous chloride saturated with hydrogen chloride with diphenylacetonitrile. The ratio of stannous salt to nitrile was $3: 1$. Following precipitation of the complex the free hydrogen halide was removed from the system by sweeping with anhydrous ammonia. The complex was decomposed with triethylamine. The molar quantity of amine was twice that of nitrile used. After recrystallization from anhydrous methanol a $6 \%$ yield of the imine was obtained. The decomposition of the complex was shown to be incomplete by the amount of aldehyde obtained from the hydrolysis of the decomposition residue. Had a larger amount of triethylamine been used, a much larger amount of Imine might well have been freed. o-Tolualdimine. The o-tolunitrile stannibromide complex of this aldimine precipitated from the reaction mixture very slowly. After initial addition of the nitrils to the athereal stannous bromide mixture the solution was saturated with hydrogen bromide at 24 hour Intervals, but only $30 \%$ of the theoretical amount of complex had precipitated after eight days. This fallure to precipitate did not Indicate a failure to react, however, for when the filtrate of the complex mixture was reduced in volume by distillation a large amount of impure complex was obtained. Decomposition of this complex with a 
four times excess of triethylamine resulted in the isolation of 11.22 of the theoretical quantity of imine monomer. Final purification of the monomer was accomplished by formation and isolation of the Imine hydrochloride followed by regeneration of the Imine with liquild amonia. If the polymeric material isolated is considered to represent an equal weight of monomer, overall yield for the reaction was $21.3 \%$.

The physical constants of the monomer are presented in Table III, while those of the derivatives prepared are in Table IV. These constants used in the Lorentz-Lorenz equation for molar refraction give a variation from the theoretical value of summed refractive equivalents of only $0.45 \%$. Spectrum II shows the infra-red spectrum of this compound.

Analysis of the prepared o-tolualdimine for nitrogen content by the semimicro Dumas method showed the compound to contain $11.84 \%$ nitrogen. o-Tolualdimine theoretically contalns $11.76 \%$ nitrogen. Analysis for total alkalinity showed a molecular weight of 120 ; that of o-tolualdimine is 119.

m-Tolualdimine. The complex of this imine was 18olated in 98\% yield. It was formed from an ether solution of stannous chloride saturated with hydrogen chloride and one-third of this molar amount of m-tolunitrile. Althosgi several decomposition agents such as diethyl and trlethylamine were used, no way was found to decompose the complex and 1solate the Imine. The decomposition step was easy, but polymerization prevented isolation of the product.

The derivatives of the complex which were prepared are listed In Table IV. 
p-Tolualdimine. This aldimine was prepared both from a stannic chloride and stannic bromide complex. In each case the molar amount of halide used was three times the molar amount of the nitrile used. The bromide complex was the only one 1solated; a $70 \%$ yleld was obtained. Decomposition of the complexes by triethylamine (five times the molar amount of nitrile used) was fairly complete, but isolation of the imine was difficult. Polymerization occurred easily. The aldimine was isolated in only $8.4 \%$ yield, but has been isolated as a derivative in $25 \%$ yield. If the weight of the polymer is considered as weight of pure imine, the yield would be $70 \%$ or more.

The physical constants of p-tolualdimine are given in Table III and the derivatives prepared are listed in Table IV. Using these physical constants in the Lorentz-Lorenz equation for molar refraction, a variation of only $1.22 \%$ from the summed refractive equivalents is observed. The infra-red absorption spectrum is shown in Spectrum III. Analysis of p-tolualdimine for nitrogen content by the semimicro Dumas method showed $11.88 \%$ nitrogen. p-Tolualdimine contains $11.76 \%$ nitrogen.

The polymer which the imine formed was a soft, sticky, brown semi-solid which hydrolysed to give a high yield of p-tolualdehyde. In non-aqueous solvents no imine was obtained on refluxing, but a change of form was often noted. Anhydrous methanol as the raflux solvent led to the formation of large well formed octahedral crystals. p-Nitrobenzaldimine. When p-nitrobenzonitrile was added to an ether solution of stannous bromide saturated with hydrogen bromide, reaction was immediate and vigorous. A large amount of yellow solid 
was quickly precipitated. When this solid complex was decomposed with triethylamine, a very good yleld of p-aminobenzonitrile was obtained. Only a trace of imine was present. This preparation was repeated several times varying conditions in an attempt to obtain the imine; only the p-amino compound resulted.

p-Aminobenzaldimine. An ether solution of stannous bromide saturated with hydrogen bromide reacted vigorously with p-aminobenzonitrile. Precipitation of a complex was immediate but neither imine nor aldehyde were obtained from attempted decomposition of the compound. Evidently a complex had formed with the amino nitrogen which in some way deactivated or protected the nitrile group.

N-Acetyl p-Aminobenzaldimine. N-Acetyl p-amicobenzontirile was trefted in the same way as the unsubstituted nitrile, and witl about the same results. Although precipltation was not as quick, this solid, like the unsubstitited complex, seemed to have the nitrilic group still intact. No method was found to treat or decompose the complex In such a way as to yleld either imine or aldehyda,

o-Chlorobenzaldimine. Addition of o-chlorobenzonitrile to an ethereal solution of stannous bromide saturated with hydrogen bromide produced immediate reaction; precipitation began after only three hours. The mixture was saturated with hydrogen bromide at 24 hour intervals for saven days; $72 \%$ of the theoretical amount of complex had precipitated by this time. Decomposition of the complex with triethylamine resulted in the isolation of $21.8 \%$ of the theoretical amount of imine. No polymer was obtained.

Physical constants of the imine and 1 ts derivatives are 1 isted 
In Tables III and IV respectively. A variation of only $0.03 \%$ from the theoretical velue of sumed refractive equivalents is given by use of these constants in the Lorentz-Lorenz equation for molar refraction. The infra-red spectrum is shown in Spectrum IV. Analysis of the imine for total alkalinity by the method of Iddings showed an equivalent weight of 139 ; the equivalent weight of o-chlorobenzaldimine is 139.5. Nitrogen analysis by the semimicro Dumas method showed a nitrogen content of $1.0 .07 \%$. Nitrogen content of o-chlorobenzaldimine is $10.03 \%$.

p-Chlorobenzaldimine. The stable intermediate of this compound was formed by reaction of $p$-chlorobenzonitrile with an ether solution of stannous bromide saturated with hydrogen bromide. The molar amount of nitrile used was one-third the wolar concentration of the stannous salt. A $99 \%$ yleld of the compl $3 x$ was obtalned when the complex mixtura was regularly saturated with hydrogen bromide over a period of ten days.

Following decomposition of the complex the imine was isolated as the hydrochlorlde in $72 \%$ yield. The solid imine was regenerated from this salt by the action of liquid ammonia. Final purification was by sublimation.

The physical constants of this aldimine are given in Table IxI and the infra-red spentrum in Spectrum $\nabla$. The derivatives which were prepared are listed in Table IV.

Analyses for the percent nitrogen of the compound by the semimicro Dumas method showed a content of $10.00 \%$. Nitrogen content of p-chlorobenzaldimine is $10.03 \%$. The equivalent weight determined by 
the non-aqueous titration method of Iddings 18 140. The equivalent weight of p-chlorobenzaldimine 18139.5.

2- and 3-Aldiminopyrldine. Addition of 2-cyanopyridine to an ethereal solution of stannous bromide saturated with hydrogen bromide resulted in a vigorous reaction ane immediate precipitation of a yellow, crystalline solid. The weight of the solid an hour after the addition of the nitrile was greater than the theoretical amount of nitrile stannibromide complex which could have been formed. Saturation with hydrogen bromide of an ethereal mixture of this solid at regular intervals over a period of four days made no apparent change. Nelther aldehyde nor imine was ottainad from the yeilow substance in any but trace amounts. It seemed probable that this nitrile had been complexed by the reaction mixture without affecting the cyano group in much the same way as the p-aminobenzonitrile previously described. There was no significant difference between the reaction of the 2- and 3-cyannpyridines when treated in this way. Although a careful study was not made, on hydrolysis the 3-cyano complex seemed to yield slightly larger amounts of aldehyde than did the 2-cyano complex. This quantity of aldehyde was still too small, however, to justify further work.

p-Aldiminobenzolc Acld. The intermediate complex of this aldimine formed from reaction of p-cyanobenzolc acid and a hydrogen bromide saturated diethyl ether solution of stannous bromide was obtained in $95 \%$ yield. The ratio of salt to nitrile used was $3: 1$; the mixture was saturated with hydrogen bromide at 24 hovr intervals for three days before filtration of the complex. Decomposition of the 
c.roplux was accomplished with a four times excess of triethylamine; the yield of Imine monomer obtalned was 26.6\%. No polymer was isolated. The physical constants of the monomer are shown in Table III, those of the derivatives of the monomer in Table IV, and the Infra-red spectrum in Spectrum VI. Use of these physical constants in the Lorentz-Lorenz equation for molar refraction shows a deviation of 1.72\% from the value obtained by suming the refractive equivalents of the molecular parts. The experimental value for the refraction was 41.2, while the theoretical one was 40.51 . The difference between the two is amall and the percent variation compares favorably with other work, but even this small yariation has a possible, and reasonable, explanation. If the addition of a carboxyl group to the benzaldimine molecule at the para position is considered an extension of conjugation in the molecule, and it normally is, then an optical exaltation would be predicted by theory (59). Since the variation between values is an exaltation, the experimental value seems to be vindicated.

Analysis by the semimicro method of Dumas showed the imine monomer to contain $9.40 \%$ nitrogen. p-Aldiminobenzoic acid contains 9.39\% nitrogen. Attempts to obtain an equivalent weight by tise determination of relative alkalinity of the compound were unsuccessful. p-Aldiminobenzaldehyde. The intermediase complex of this imine was prepared using a nitrile to salt ratio of $3: 1$. Only 0.1 mole of the nitrile was avallable for use, consequently the amount of solid preclpitating from the reaction mixture was not great. Four days after addition of the nitrile, triethylamine was added to the mixture 
until decomposition was complete. The amount of amine used in the composition was three times the amount of nitrile used in complex formation. No aldimine was isolated. However, it was possible to prepare derivatives of terephthalaidehyde from the decomposition filtrate. These derivatives are presented in Table IV.

It is surprising that at least some aldimine was not isolated. The reason seemed to be a failure in complex formation. Infra-red spectra of the decomposition filtrate showed the presence of a relatively large amount of nitrile.

$\alpha$-Naphthaldimine. Addition of 0.1 moles of $\propto$-naphthonitrile to 0.3 moles of ethereal stannous bromide complex resulted in immediate reaction, but precipitation did not occur for three days. The complexes of all the other imines prepared were white or pale yellow, but that of $\alpha$-naphthaldimine was a bright medium green. The complex mixture was saturated daily with hydrogen bromide but after six daya only $15.4 \%$ of the theoretical amount of the complex had precipiteted. The entire reaction mixture along with the precipitated solid was subjected to decomposition by triethylamine. The imine was isolated in $49.5 \%$ yield.

Nitrogen analysis by the semimicro Dumas method showed a nitrogen content of 9.01\%. $\propto$-Naphthaldimine contains $9.03 \%$ nitrogen. Physical constants of the compound are shown In Table III. The derivetives which were prepared are listed in Table IV.

$\alpha$-Naphthyiacetaidimine. A molar ratio of $\alpha$-naphthylacetonitrile to ethereal stannous complex of $1: 3$ was used in forming the stannic complex of this aldimine. The mixture was saturated daily 
with anhydrous hydrogen bromida, but after eight days only 1.37 of the theoretical quantity of the yellow complex had precipitated. Decomposition of the stannic complex was accomplished by addition of an excess of triethylamine to the complex reaction mixture. The imine was isolated from the decomposition filtrate as the hydrochloride, and, after thorough washing of the salt with diethyl ether, was regenerated with liquid ammonia. A yield of $23 \%$ was obtained.

The physical constants of $\alpha$-naphthylacetaldimine are given In Table III and the derivatives prepared are listed in Table IV. The Infra-red spectrum is shown in Spectrum VII. Analysis of the aldimine for nitrogen content by the semimicro Dumas method showed $8.33 \%$ nitrogen. $\alpha$-Naphthylacetaldimine contains $8.28 \%$ nitrogen. o-Trichloromethylbenzaldimine. Although a $3: 1$ mixture of stannous complex and o-trichloromethylbenzonitrile had been saturated daily with hydrogen bromide, no stannic complex hed precifltated after five days. This mixture was trested with an excess of triethylemine and the decomposition products were very thoroughly washed with dry ether. When the decomposition filtrate was reduced in volume, a large amount of dark brown, imine containing material was obtained. After distillation of this substance, the aldimine fraction was further purified by preparation and isolation of the imine hydrochloride. The Imine was regenerated with liquid ammonia. A yield of $44 \%$ was obtained.

The physical constants of o-trichloromethylbenzaldimine are given in Table III. The derivatives of the imine and its hydrolysis product are given in Table IV. The infra-red spectrum of the compound is given in Spactrum VIII. 
Analysis by the semimicro Dumas method showed a nitrogen content for the prepared aldimine of $5.87 \%$. Determination of the total alkalinity for the compound by the method of Iddings showed an equivalent waight of 220. o-Trichloromethylbenzaldimine contains 5.843 nitrogen and has an equivalent weight of 222.5 . p-Trichloromethylbenzaldimine. p-Trichloromethylbenzonitrile was insoluble in diethyl ather, but, on addition of the compound to three times its molar quantity of ethereal stannous bromide complex, solution was immediate. Reaction was not vigorous but precipitation occurred within 15 minutes of the addition of the nitrile. On isolation four hours after initial precipltation the yellow precipitate weighed twice the theoretical amount of the complex. Decomposition of this solid with triethylamine resulted in the isolation of about $1 \%$ of the theoretical amount of aldimine. Th1s small yield was not due to lack of decomposition agent for a three times molar excess of amine was used initially on decomposition. After the small amouns of imine resulting became apparent, further decomposition of the initial decomposition precipitate was attempted with no effect. A possible explanation for this small yield may be the insolubility of the imine in diethyl ether. Since p-trichloromethylbenzonitrile is very insoluble in diethyl ether, one would not expect the imins to be very soluble in this solvent. Tests with the isolated imine support this conclusion. It seems possible that more of the aldimine was formed in the reaction mixture but was simply not removed by the solvent. Insufficient quantities of the compound were prepared to make analysis possible. The melting point of the compound is shown in 
Table III and those of Its del:Ivatives are shown in Table IV.

Pxaparation of Derf.vatives. As a atep in the identification and characterization of the aldimines a series of derivatives were prepazed. These were of two types. One group was prepared from the Imine Itself; the other was of the hydrolysis product, the corresponding aldehyde, of the imine. These derivatives are Iisted in Table IV. Four Imine derivatives were prepared; these were the hydrochlorides; benzenesulfonamides, oxalates, and phenylthioureas.

The Imine hydrochlorides were prepared by mixing equal volumes of ether saturated with hydrogen chloride and a dilute ethoreal imine solution. Precipitation was immediate. The precipitates were thoroughly washed with anhydrons ether and dried under vacuum.

The benzenesul fonamide derivatives were prepared by mixing equal parts of benzenesulfonyl chloride and a $1: 1$ solution of absolute ethanol and imine, and warming the mixture. The mixture was cooled after five minutes to $0^{\circ} \mathrm{C}$, and a $10 \%$ sodium hydroxide solution was added slowly and with shaking until reaction ceased. The derivatives were recrystallized from ethanol.

Oximides were prepared by holling a $2: 1$ mixture of ethyl oxalate and imine for two minuies. The product was recrystallized from ethanol.

In preparing the phenylthiourea derivatives equal parts of phenyl 18othiocyanate and inine were mixed, and the mixture was boiled for two minutes. The mixture was then cooled to $0^{\circ} \mathrm{C}$, filtered, and washed with ligroin and $50 \%$ ethanol. Recrystallization was from $95 \%$ ethanol. 
TABLB III

PHYSICAL CONSTANTS OF THE PREPARED ALDIMINNES

\begin{tabular}{|c|c|c|c|c|}
\hline Imine & ${ }_{{ }_{C}}^{M_{0}} P_{.}$ & $\begin{array}{l}\text { B.P. } \\
{ }^{\circ} \mathrm{C} / \mathrm{mm}\end{array}$ & $d_{4}^{20}$ & $n_{D}^{20}$ \\
\hline Benzalàimine & & $58 / 4$ & 0.9799 & 1.5259 \\
\hline Phenylacetaldimine & & $212 / 731$ & & 1.5251 \\
\hline Diphenylacetaldimine & 129 & & & \\
\hline o-Tolualdimine & & $192 / 734$ & 0.9586 & 1.5212 \\
\hline p-Tolualdimine & & $35 / 1.1$ & 1.002 & 1.5358 \\
\hline o-Chlorobenzaldimine & & $177 / 733$ & 1.1912 & 1.5589 \\
\hline p-Chlorotenzaldimine & 48 & & & \\
\hline p-Aldiminobenzoic Acid & & $182 / 733$ & 1.0505 & 1.4927 \\
\hline$\alpha$-Naphthaldimine & 37 & $267 / 734$ & & \\
\hline$\alpha$-Naphthylacetaldimine & 85 & $115 / 728$ & & \\
\hline o-Trichloromethylbenzaldimine & 112 & $208 / 728$ & & \\
\hline p-Trichloromethylbenzaldimine & 135 & & & \\
\hline
\end{tabular}


Because of the ease of hydrolysis of aldimines, hydrolysis of the imine prior to the preparation of an aldehyde derivative was not necessary. The aldimines were simply mixed with aqueous solutions of the reagents as if they had been already hydrolysed to the aldehyde. The aldehyde derivatives which were prepared are the 2,4 dinitrophenylhydrazones, the semicarbazones, and the oximes. These were prepared according to the directions on derivative preparation in Shriner and Fus on's "Identification of Organic Compounds" (60).

Infra-red Spectra. In recording the infra-red spectra of the aldimines two instruments wose used. Spectra I - VIII were recordud on a Perkin-Elmer Infracord Spectrophotometer. This instrument has the advantage of being quick and easy to use and records the absorption spectrum in a space only 9.5 inches in length. Although this short recording space lessens the resolution of the spectrum, the recorded spectrum is much easier to handle and resolution is still sufficient for all but quantitative spectral studies. In the benzaldimine polymerization study previously described greater resolution of the absorption spectra was desirable in order that any change in the reaction mixtures would be easily apparent. For this reason these spectra were recordad using a Perkin-Blmer Infra-red Spactrometer, model 12c. Only the four points of variation in the spectra of the reaction mixtures are shows in Figure I because the spectral recordings are 4.5 feet in length. The entire benzaldimine spectrum is shown in Spectrum I.

The spectrum of p-tolualdimine, Spectrum III, was recorded from a carbon tetrachloride solution of the imine. All other spectra 
TABLE IV

DERIVATIVES OF THE PREPARED ALDIMINES

\begin{tabular}{|c|c|c|c|c|c|c|c|}
\hline \multirow[t]{2}{*}{ Imine } & \multicolumn{7}{|c|}{ Derivatives* $\left(\right.$ M.P. $\left.{ }^{\circ} \mathrm{C}\right)$} \\
\hline & A & B & C & D & $\mathbf{E}$ & $\mathbf{F}$ & G \\
\hline Benzaldimine & $235-6$ & 203 & 222 & 35 & & & \\
\hline Phenylacetaldimine & 110 & 173 & $153-4$ & & $84-86$ & & \\
\hline Diphenylacetaldimine & & & & 120 & & & \\
\hline o-Tolualdimine & 193 & 239 & 212 & & & & $225 d$ \\
\hline m-Tolualdimine & 194 & & $203-5$ & & 200 & 200 & \\
\hline p-Tolualdimine & 234 & & 233 & & & $212 d$ & \\
\hline o-Chlorobenzaldimine & 206 & 111 & 226 & & & & \\
\hline p-Chlorobenzaldimine & $264 d$ & 226 & 230 & & & 149 & \\
\hline o-Trichloromethylbenzaldimine & 111 & 194 & & & & & 212 \\
\hline p-Trichloromethylbenzaldimine & 112 & 172 & & 209 & & & \\
\hline p-Aldiminobenzoic Acid & $287 d$ & 237 & 199 & 209 & & & \\
\hline p-Aldehydobenzaldimine & $278 d$ & & & 155 & & & \\
\hline$\alpha$-Naphthaldimine & & 195 & 221 & 98 & & & 292 \\
\hline$\alpha$-Naphthylacetaldimine & & 65 & 208 & $118-9$ & & & 223 \\
\hline $\begin{array}{l}\text { * A - 2,4 Dinitrophenylhydraz } \\
\text { B - Hydrochloride } \\
\text { C - Semicarbazone } \\
\text { D - Oxime } \\
\text { E - Benzenesulfonamide } \\
\text { F - Oximide } \\
\text { G - Phenylthioures } \\
\text { d - with decomposition }\end{array}$ & & & & & & & \\
\hline
\end{tabular}


were recorded using the pure aldimine.

It has been reported (61) that the characteristic absorption bands of the imine group, the $-C=N-$, and $=N-H$ absorption bands, fall in the ranges $5.7-5.8 \mu$ and $3.3-3.5 \mu$ respectively when recorded from secondary imines. It is of interest that only a very small shift from the ketimine absorption bands is shown by the aldimine spectra. This shift is in the direction of $3 \mu$. 
FIGURE II

SPECTRUM I - INFRA-RED ABSORPTION SPECTRUM OF BENZALDTMINE

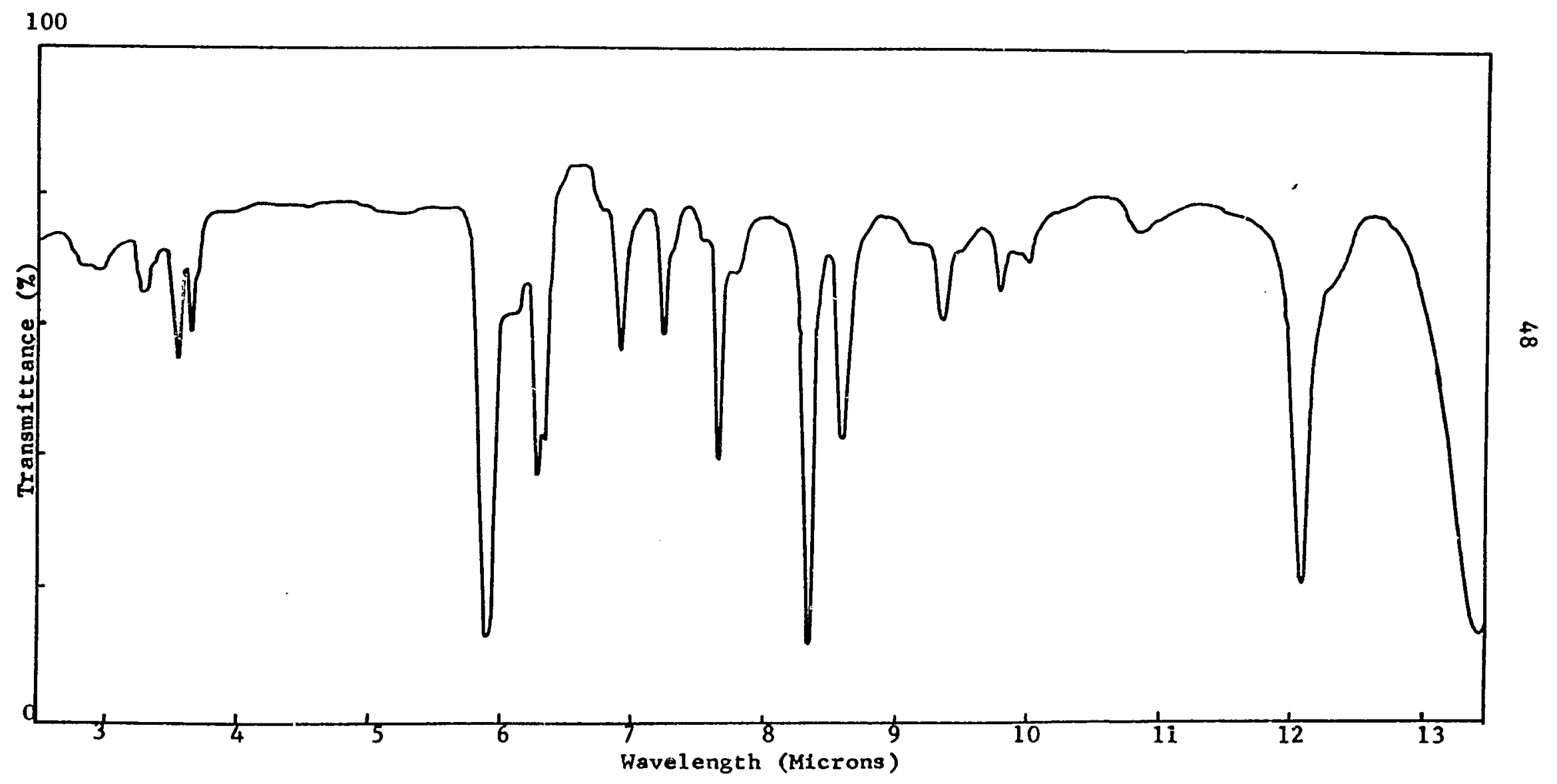


FIGURE III

SPECTRUM II - INFRA-RED ABSORPTION SPECTRUM OF O-TOLUALDIMINE

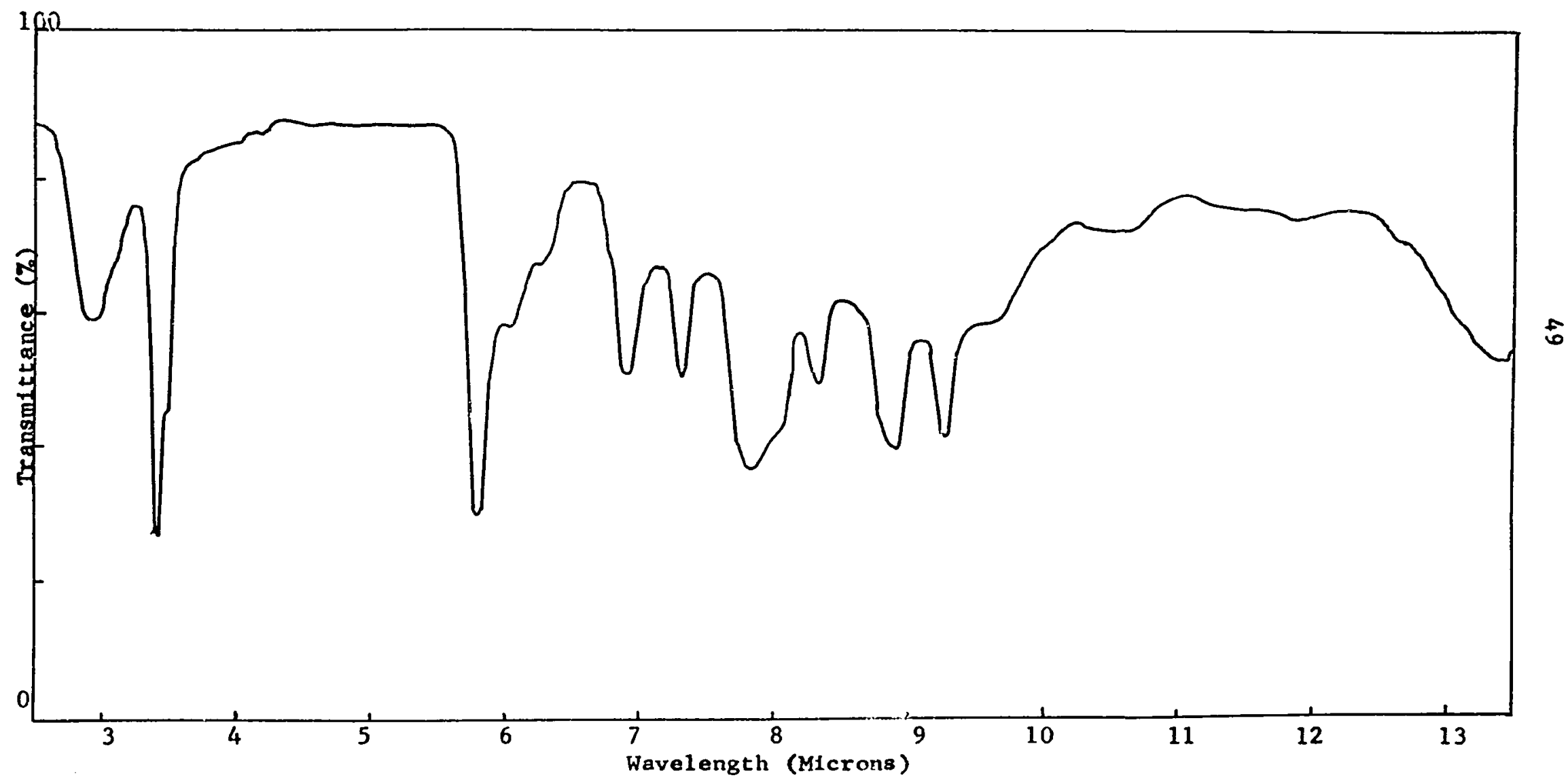


FIGURE IV

SPECTRUM III - INFRA-RED ABSORPTION SPECTRUM OF P-TOLUALDIMINE

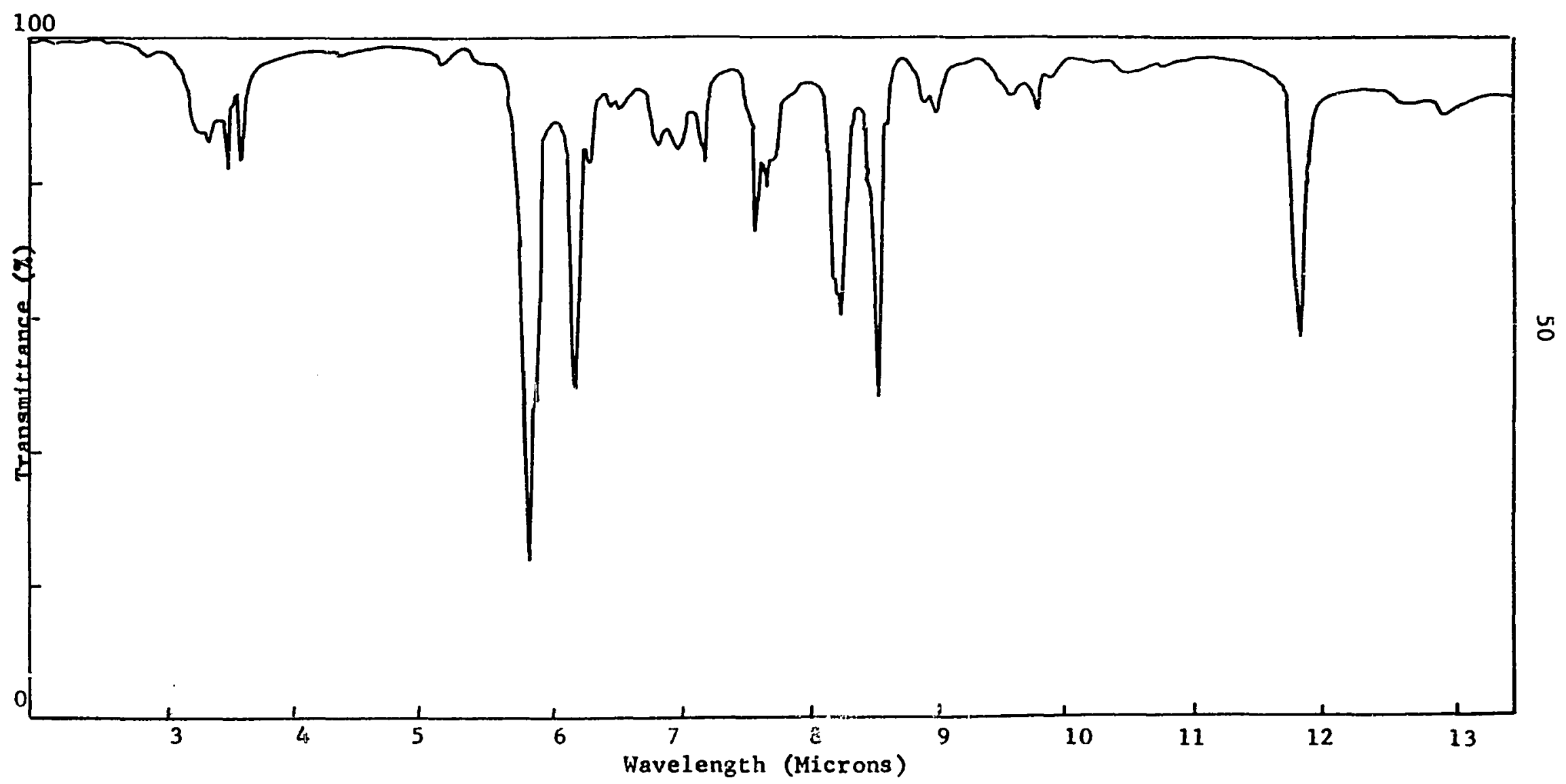


EIGURE V

SPECTRUM IV - INFRA-RED ABSORPTION SPECTRUM OF O-CHLOROBENZALDIMINE

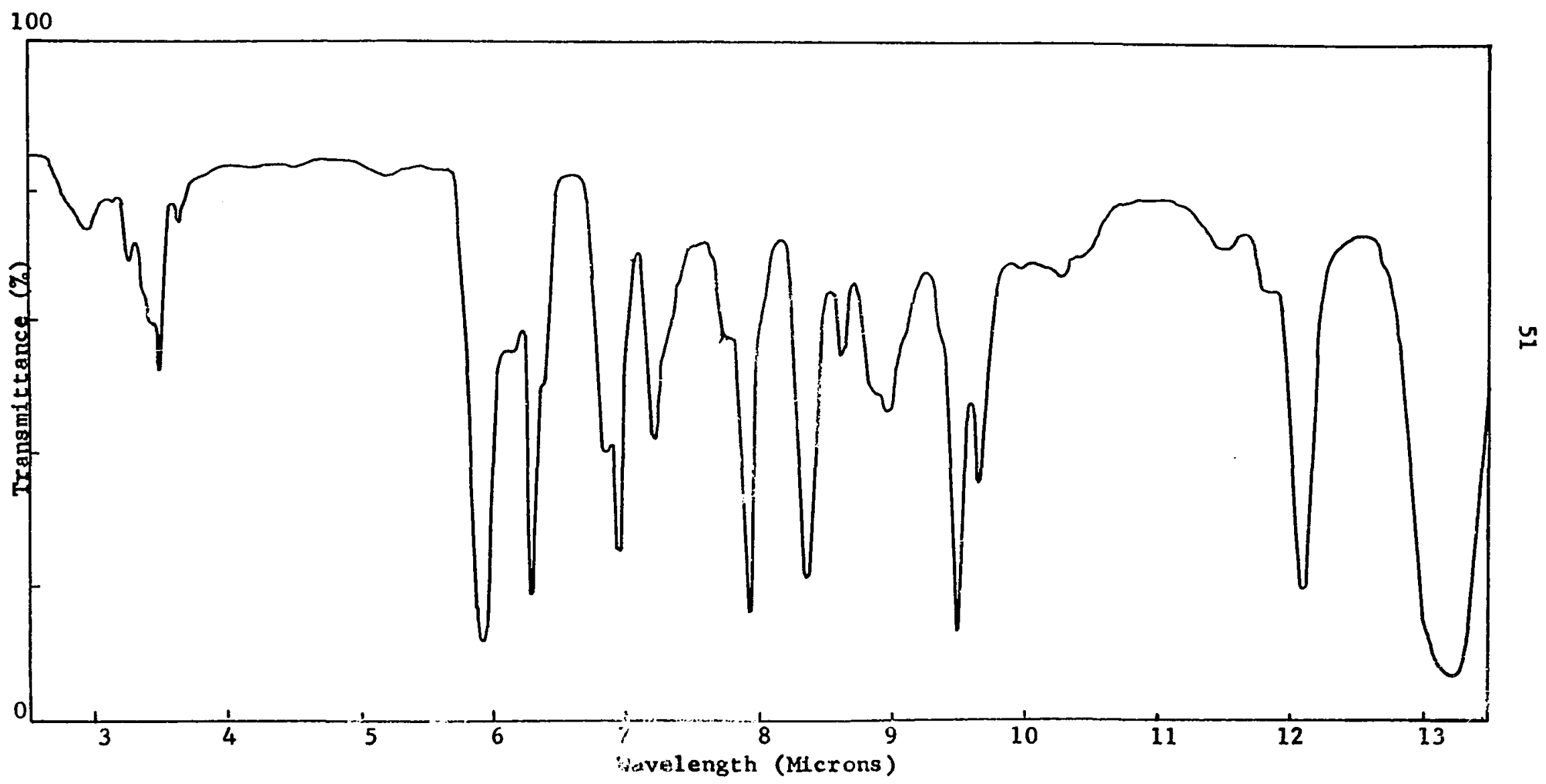


FIGUK: VI

SPECTRUM V - INERA-RED ABSCRPTION SPECTRUM OF P-CHI TROBENZALDIMINE

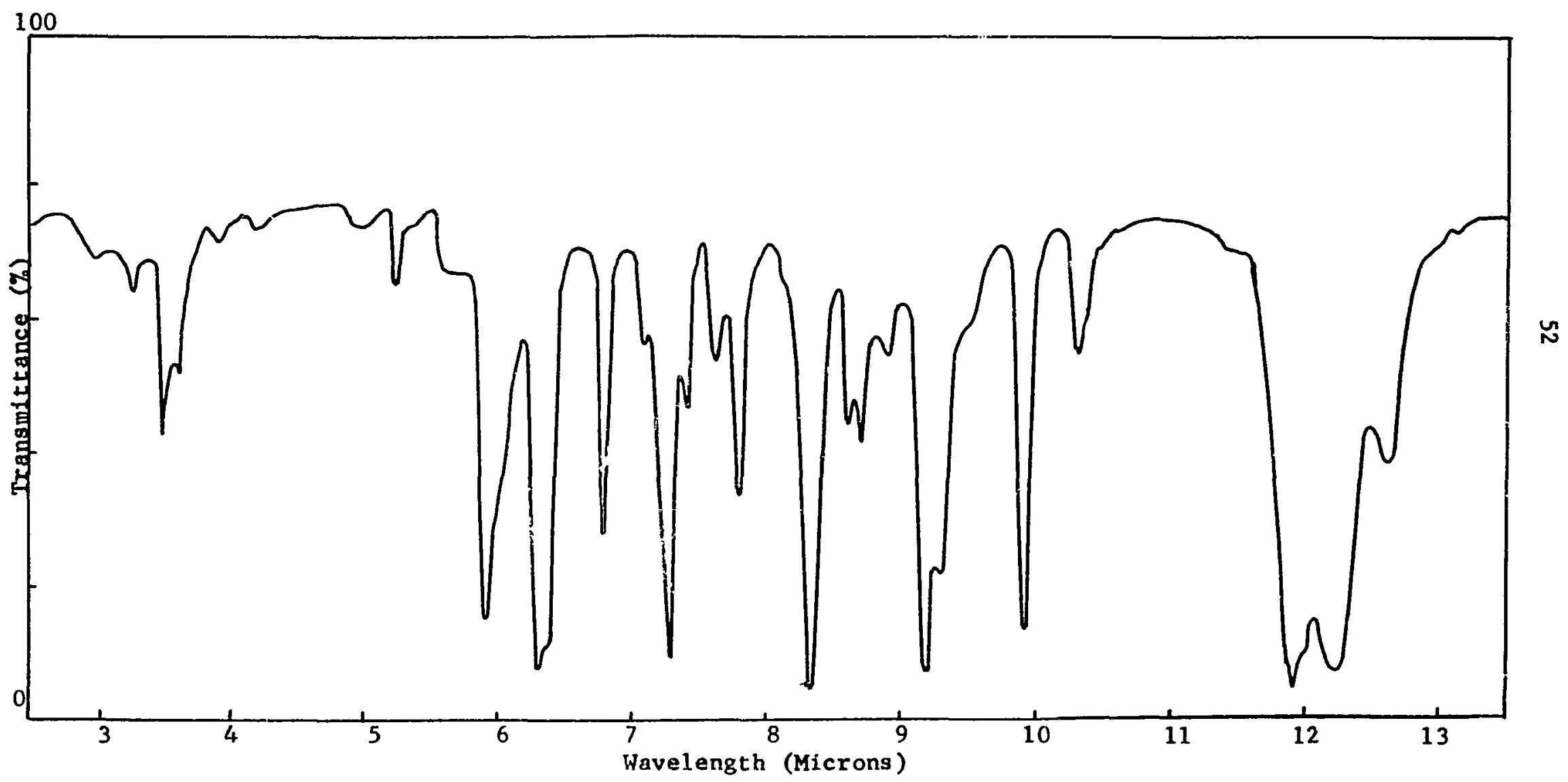


FIGURE VII

SPECTRUM VI - INFRA-RED ABSORPTION SPECTRUM OF P-ALDIMTNOBENZOIC ACID

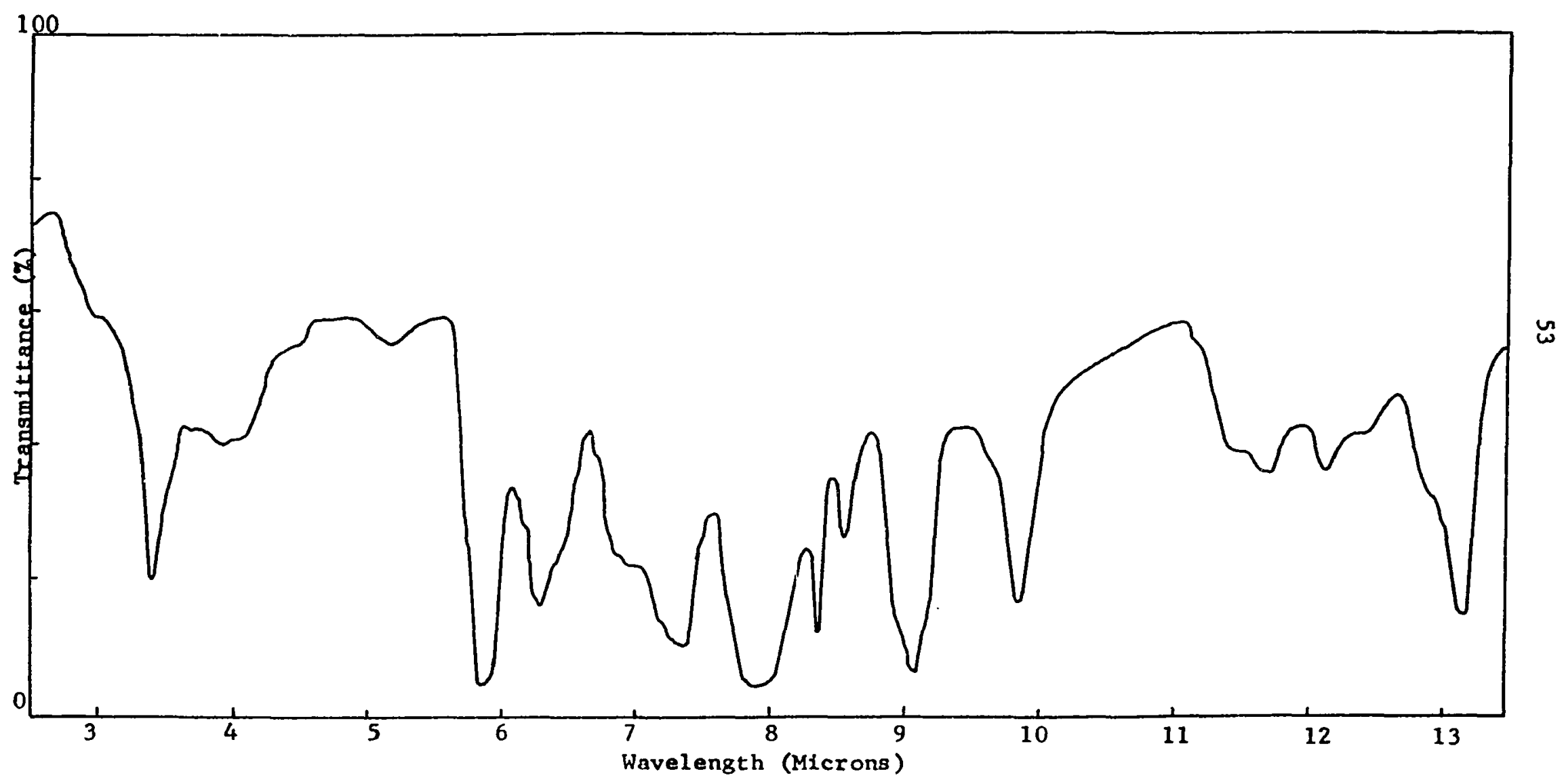


SPECTRUM VII - INFRA-RED ABSORPTION SPECTRUM OF $\propto$-NAPHTHYLACETALD MMINE

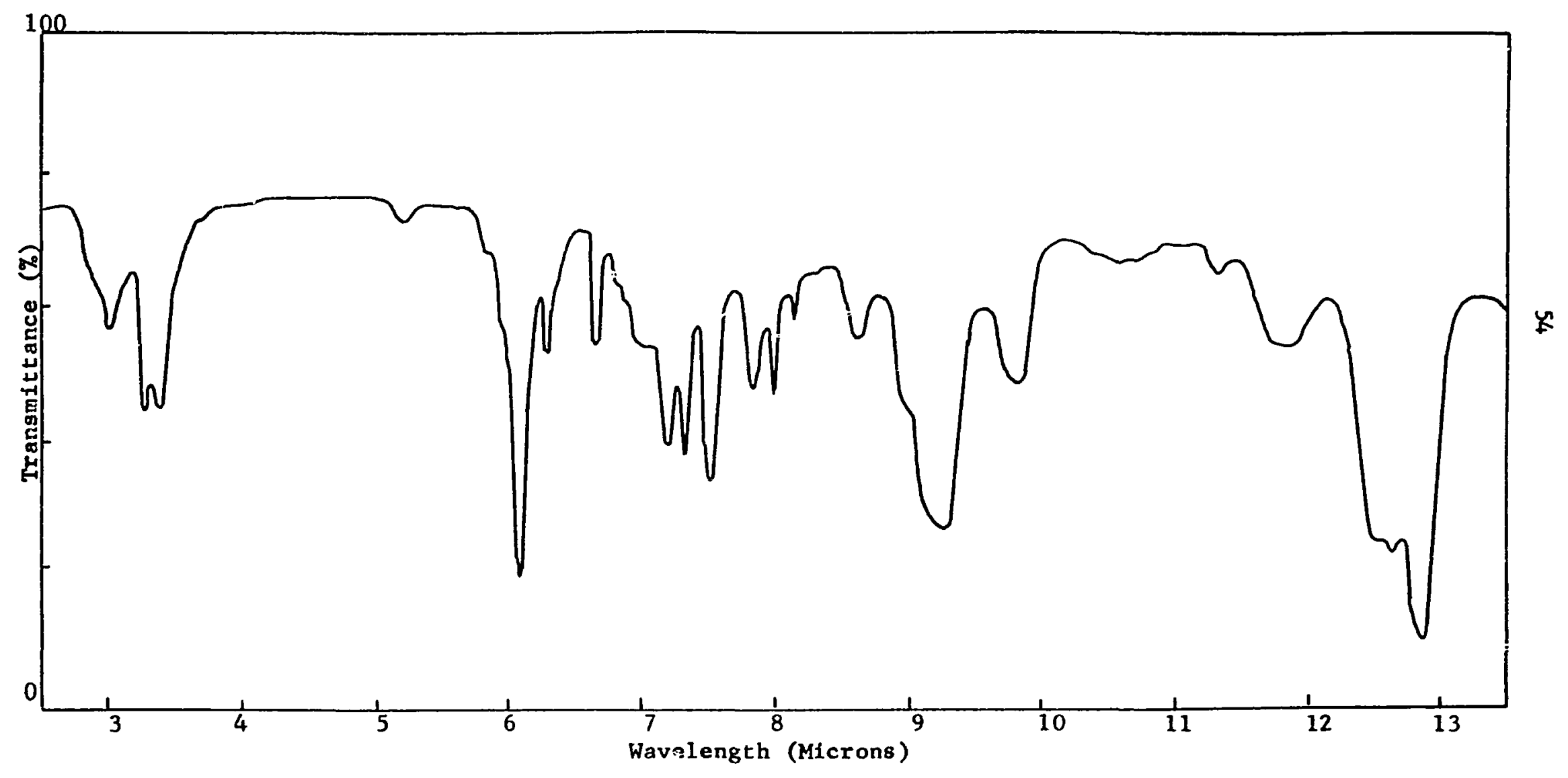


FIGURE IX

SPECTRUM VIII - INFRA-RED ABSORPTION SPECTRUM OF O-TRICHLOR OMETHYLBENZALDTMINE

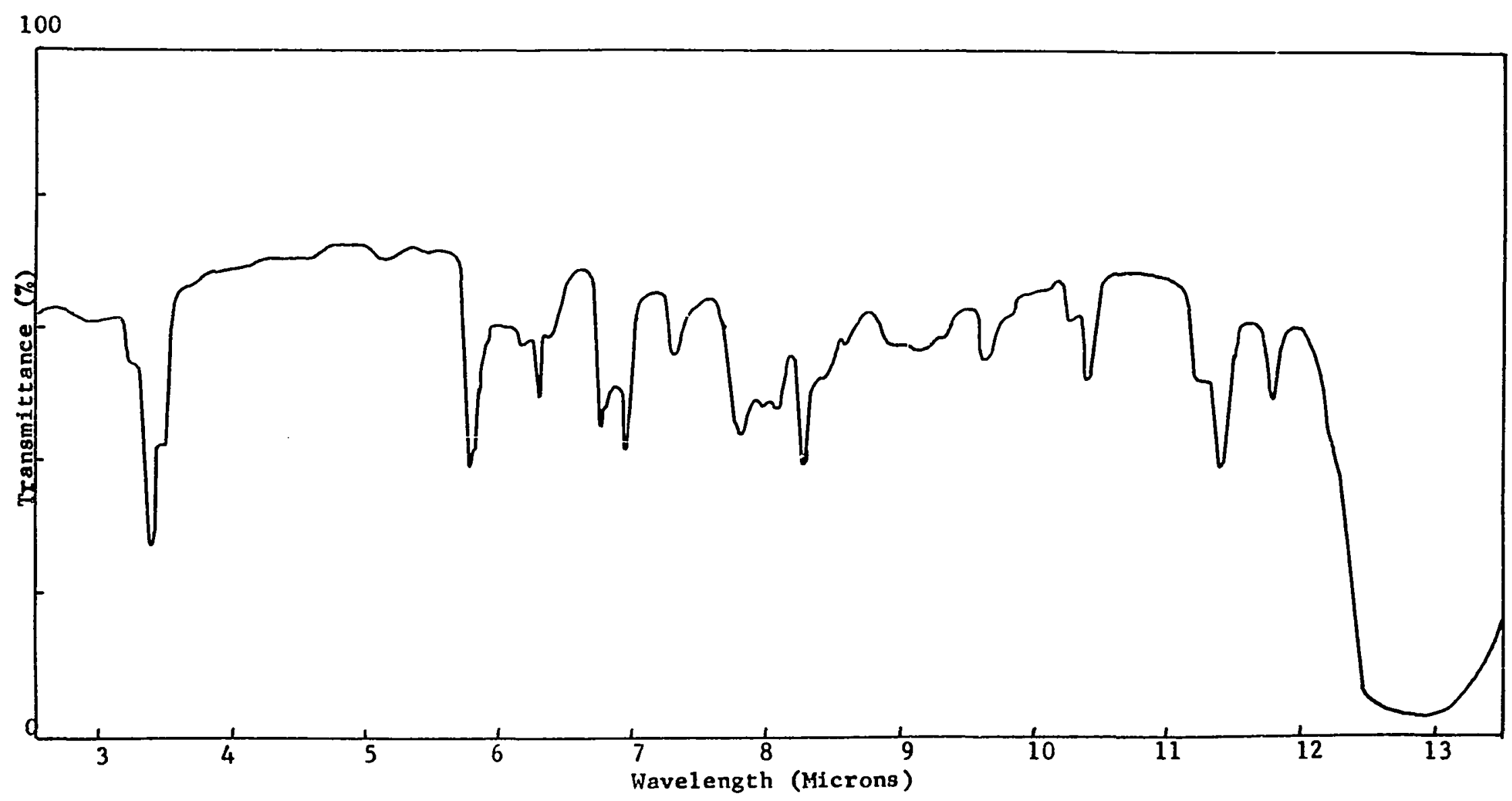




\section{CRAPTER III}

\section{REIATED EXPERIMENTAL}

This chapter is devoted to the discussion of preparations and procedures which were performed but which are not directly connected with imine preparation and fsolation.

Preparation of Cerous Chloride. A1though chromous, vanadous, and titanous salts had been reported (16) as ineffective replacements for stannous halides in the Stephen reaction, it was felt that cerous salts might be effectively used. Unfortunately the only cerous halide available was cerous chloride heptahydrate and all attempts to dehydrate the salt proved unsuccessful. The cerous ion was consequently not tried as a reducing agent for nitriles.

The attempts at dehydration of the heptahydrate included the use of heat and vacuum, dehydrating agents such as magnesium perchlorate in an evacuated, heated system, and partial solution of the salts In solvents which form azeotropes with water. The last method was the most successful. Using ethanol as the solvent and long periods of reflux followed by careful distillation, some of the cerous salt was prepared which contained only 0.20 moles of water per mole of salt. This was the most nearly anhydrous form of the salt obtained, and this contained far too much wator for use in imine preparation. Although 
further dehydration of the salt was probably possible, production of sufficlent quantities of the reducing agent by this method did not seenr pricticial and the attempt was abandoned. Analysis of the varions cerous chloride hydrates which were produced was by the volumetric sodium bismuthate method of Metzger. The procedure as presented in volume one of "Scott's Standard Methods of Chemical Analysis" (62) was followed exactly.

$$
\text { Analysis of Stannous Bromide. Analysis of the stennous }
$$

bromide which was used was by electrolytic deposition of the tin from an oxalic actid solution. The analysis was done on a Sargent-slomin Blectrolytic Alialyser; the electrodes used were copper. The general method of analysis is presented in B. J. S. Sand's "Blectrosiemistry and Electrochemical Analysis" (63). Analysis showed the stannous bromide used to be $98.5 \%$ pure.

\section{Ereparation of Standard Solutions for Alkalinity Titrations.}

Sevaral of the aldimines which were prepered were titrated for total alkalinity, the results being used as a measure of purity and as a method of determining equivalent weight. The method was developed for use with imines by Iddings (58); it involves the nonaqueous potentiometric titration of the imine in a leveling solvent.

Glacial acetic acid was used as the solvent for the titrations. The titrating agent was perchloric acid. A standard $0.1 \mathrm{~N}$ solution of this acid was prepared by mixing $9 \mathrm{mls}$. of $72 \%$ perchioric acid in 8 mall portions with $50 \mathrm{mls}$. of glacial acetic acid at $0^{\circ} \mathrm{C}$. This mixture was diluted to volume with glacial acetic acid in a $1000 \mathrm{ml}$. volumetric flask. This solution was standardized against a solution of standard 
base. The basic standard was prepared using potaselum acid phthalate as a primary standard in glacial acetic acid.

Pranaration of p-Cyanobenzylbromide. Th1s compound was

prepared by the photobromination of p-tolunitrile using liquid bromine and light from a 200 watt, unfrosted, incandescent light bulb. The method was developed by R. C. Fuson (64). The compound was obtained In $47 \%$ yield.

Preparation of Salicylaldoxime. Salicylaldoxime was prepared in $90 \%$ yield by the method of Raiford and clark (65). The general method was the reaction of salicylaldehyde and hydroxylamine hydrochloride in an alkaline solution.

Preparation of Benzaldimine by the Method of H. H. Strain. In 1927 H. H. Strain (8) reported the preparation of a compound he belleved to be benzaldimine. The compound was prepared by allowing hydrobenzamide to slowly dissolve over a period of $30-40$ hours in liquid ammonia containing a trace of ammonium chloride. Concentration and cooling of the mixture resulted in the separation of the imine as a crystallizable ofl. Decomposition of the large, transparent crystals of imine occurred if it was dissolved in any solvent other than liquid ammonia. The melting point was that of hydrobenzamide. Many of the reactions reported are also those of hydrobenzamide.

Since the properties and reactions of Strain's compound are so different from those of the compound isolated and reported in this work as benzaidimine, an effort was made to prepare the compound which Strain reported. Four attempts were made to repeat the reported work; all were unsuccessful. The directions given in the report were 
followed exactly in the first preparation. When this was unsuccessful, the amount of hydrobenzumide was varied and additional time for reaction allowed. Although both mora and 1 ess amide per volume of ammonia was used, nelther ofl nor cryetals were obtained. In the last proparation, the amount of ammonium chloride used was increased; Strain's report mentioned that an acid should be used in the reaction. Again nothing was found on concentration of the mixture but ammonia, ammonium chlorice and hydrobanzamide. The preparation was not pursued further. 
CHAPTER IV

\section{DISSCUSSION OF RESULTS}

Previous workers have reported the preparation and isolation of five aldimines; these are benz:aldimine, phenylacetaldimine, diphenylacetaldimine, acetaldimine, and $\alpha$-methoxyacetaldimine. In this work attempts were made to prepare and characterize the first three of these, but only the preparations of benzaldimine and diphenylacetaldimine were succesgful. This chapter is devoted to a discussion of possible reasons for the variations in description of benzaldimine as previously reported and as reported here, and to possible reasons for the lack of success in preparing phenylacetaldimine. In the course of preparing the compounds described in Chapter II patterns of imine reactivity and of yields obtained have evolved which seem to suggest ways in which imines may react. These are also discussed. Benzaldimine and its derivatives have been investigated by more workers than any other aldimine. Unfortunately there has been very little agreement as to its properties. It was pointed out in Chapter I that because of this disagreement special care was taken in purification aod characterization of the compound described there as benzaldimine. Derivatives were prepared which show the presence of a basic and incompletely subatituted nitrogen, while others were 
prepared which collectively characterize the hydrolysio product of the compound. After comparison of the physical constants of the derivatives of the hydrolysis product with the values reported for the derivatives of various aldehydes, there can be little doubt that this product is benzaldehyde. The nitrogen compound prepared was subjected to two entirely different types of analysis. The total alkalinity, and from this an equivalent weight, was determined; in the second analysis the nitrogen content was found by the well known, semimicro Dumas method. In each case the value obtained agreed with that of benzaldimine. The presence and type of nitrogen in the compound and the structure of the non-nitrogen containing portion of the molecule had been shown by derivative preparation, and analyses of two types concurred with the proposed structure. It remained only to show the structural relationships of the intact molecule. An indication of this structure is given by the infra-red spectrum of the prepared compound. Study of this spectrum, presented in Chapter II, shows absozption bands falling in the ranges of absorption of the $=\mathrm{N}-\mathrm{H}$, and $-\mathrm{C}=\mathrm{N}-$ groups. The remaining portions of the spectrum show absorption in the regions usually associated with mono-substituted benzenoid compounds. On the basis of all the evidence, it seems highly probable that the prepared compound is benzaldimine.

The physical constants of benzaldimine and its derivatives reported by other workers and in this study are shown in Table V. The values presented in Chapter II and those of Grignard and Escourrou (6) for density and refractive index differ too greatly to be explained on the basis of the temperatures at which the determinations were made. 
The French authors prepared their compound by the catalytic hydrogenation of benzonitrile using nickel as a catalyst. Their report mentions difficulty in obtaining pure, stable imine by distillation and that some benzylamine was formed in the hydrogenation reaction. For this reason if seems possible that the sample of benzaldimine which they obtained was not entirely pure and that the reported physical constants are those of a mixture. That the sample of Grignard and Escourrou did contain some of the imine is substantiated by the agreement in melting point of the hydrochloride derivative reported by them and in this report.

It was mentioned in Chapter I that this same imine hydrochloride was reported in an earlier article by M. Busch (5). The melting point reported was $22^{\circ} \mathrm{C}$ lower than that found by the French workers and in this study. This wide variation would lead one to suspect either another compound or an impure sample.

In Chapter III the unsuccessful attempts to repeat H. H. Strain's preparation of "benzaldimine" are described. This compound is described by Strain as translusent crystals unstable in any medium, including dry air, other than liquid amonia. No derivatives, of the nitrogen portion of the molecule, such as the hydrochloride, are reported; aldehyde derivatives are reported. This substance which Strain describes is very unlike the one described in Chapter II and by Grignard and Escourrou. In consideration of the evidence supporting the structure of the compound prepared and reported here, it seems likely that the translucant crystals were not benzaldimine.

Catalytic hydrogenation of phenylacetonitrile was used by 
Grignard and Becourrou to obtain phenylacetaldimine. They purified the compound by distillation at atmospheric pressure and describe it as buing stable and easily handled. The stability under these conditions is not surprising for a compound of this type and molecular waight. However, when one considers that the imine is a tautomer of styrylamine and that the amine is the more conjugated form, some tendency to tautomerlzation and polymerization might well be expected. The occurrence of a low melting polymer is mentioned in the French article, but no indication of a rapid or spontaneous polymerization is given. Many attempts to prepars phenyiacetaldimine were made, but a stable monomer such as was described by Grignard and Bscourrou was never obtained. The preparation of the monomer in solution and its rapid polymerization on concentration or distillation has been described. Bven when a fraction of monomer was obtained by vacuum distillation, formation of a polymer from the fraction was almost immediate. Free radical scavangers in the system only slowed polymerization and changed the form of polymer obtained. The refractive index of the monomer, even when determined immediately after distillation, was markedly different from that of the earlier report.

One explanation of the discrepancy between the French report and this work which seems plausible is that the compounds were formed in different ways and 80 contalned different impurities. In each case the nitrile was reduced to the imine, but in the earlier case the reaction was catalytic while in this work a chemical reduction was used. Tin compounds are often used as polymerization agents; some of these same compounds are quite volatile. Undoubtedly, any unrefined, Imine 
monomer solution which was prepared contained a variety of tin containing impurities. These might easily have been the cause of polymerization on conticentration of the solution. Because of their volatility, these same impurities might possibly have been distilled or entrained along with monomer in a distillation. If such were the case, the distilled imine might also polymerize. These explanations are supposition. It is certain, however, that for some reason the phenylacetaldimine prepared in this work polymerized, while that of Grignard and Escourrou did not. No explanation is offered for the very great difference between the refractive Index reported and the one found. Although the imine hydrochloride obtained was thoroughly washed and was reprecipitated after isolation of the salt and regeneration of the Imine with liquid ammonia, it melted $7^{\circ} \mathrm{C}$ lower than that reported in the French article.

The physical constants of the solid diphenylacetaldimine and its derivatives which were prepared agreed with those obtained by Kohler and Drake (9) in 1923. Although the yield of the imine was small due to incomplete decomposition of the intermediate complex, sufficient anounts of the compound were obtained to identify it as the imine reported in 1923. Th1s compound darkens and forms a polymer-11ke material when held above its melting point for a few minutes, but no polymeric material was isolated in its preparation. Since the impurities present in the imine solution resulting from decomposition of the intermedilate complex were undoubtedly much the same as those present in an unrefined solution of phenylacetaldimine, the lack of polymerization must be ascribed to factors other than impurity. The primary factors 
here were probably that the compound crystallized on concertration of its solution and that it was purified by recrystallization rather than distillation. The milder conditions of purification and the removal of monomer from solution by precipitation could have made a great deal of difference in the rate and amount of polymerization which occurred. Some contribution to stability, however, may have come from steric hindrance to reaction by the phenyl groups on the carbon atom adjacent to the imine group. Ths isolation of a substantial amount of $\alpha$-naphthylacetaldimine, a substituted acetaldimine with a large group adjacent to the imine group, seems to support the possibility of a steric eftact.

Table VI shows the relative amounts of intermediate precipitate, 18olated monomer, and isolated polymer plus monomer obtained from the preparatimn of $\mathrm{f}, \mathrm{h}$ h aldimine. Generally speaking the ylelds of 18olated conpits and of polymer plus monomer were good, but the amount of monoiner isoleted was low. Bxceptions to this in which a fairly high yield of nomeric imine was obtained were in those cases where the imine grouj pas alone on a benzene ring or where other substituents on the ring were of an electron withdrawing nature. Polymerization was greatest and the most rapid with the aliphatic, substituted, acetaldimine, and the benzaldimines substituted with electron donating groups.

This study was not extensive enough to give a definite and positive picture of the sase with which imines could be prepared and 1solated. Howevex, t3y hata obtained did seem to indicate certain patterns of stability and reactivity. Any conclusions drawn from this 
Information were still supposition, but had encugh basis to be of value in pointing out areas of attack and study in the later work. Possible reas on for the reactivity of the aldimines containing an alpha hydrogen atom have been discussed earlier in this chapter, and the appazent stability of the completely conjugated imines, benzaldimine and $\alpha$-naphthaldimine, might have been expected. An area of particular interest which one might not have predicted, however, is the large apparent difference in reactivity of the monosubstituted benzaldimines. Although complete Information is lacking, the benzalidmines substituted with electron withdrawing groups seem considerably less reactive, and hence more easily isolable, than those substituted with electron donars. Such reactivity might be laken as support for an imine reaction mechanism in which an additional electron supply is required by the imine double bond for spontanoous reaction at room temperature. All of these compounds seem to react with themselves if enough heat energy Is supplind, but apparently only those richly supplied with electrons have suffieient energy at room temperature for immediate reaction. Thorough testing of this idea remains to be done. The way is open for some very interesting future studies, now that a definite method of aldimine preparstion and isolation has been developed. In addition to the studies of inductive effects on imine reactivity previously mentioned, there are several areas of study which should be especially interesting and productive. Among these are comparisons of steric effects in influencing yield and compound stability; determinations of the ease with which incompletely conjugated aldimines tautomerize, and comparisons of reactivity of unsubstituted allphatic and aromatic aldimines. 
TABLE V

COMPARISON OF PHYSICAL CONSTANTS

Benzaldimine and its derivetives

\begin{tabular}{|c|c|c|c|c|c|c|c|}
\hline Data Source & M.P. & B.P. & $\begin{array}{c}\text { Refractive } \\
\text { Index }\end{array}$ & Density & M.P. (A*) & M.P. (B*) & M.P. (C*) \\
\hline Busch (5) & & & & & $181^{\circ} \mathrm{C}$ & & \\
\hline $\begin{array}{l}\text { Grignard and } \\
\text { Escourrou (6) }\end{array}$ & & $140^{\circ} \mathrm{C} / 50 \mathrm{~mm}$ & $\begin{array}{l}n_{D}^{12} \\
1.5725\end{array}$ & $\begin{array}{l}d^{13} \\
i .009\end{array}$ & $203-240^{\circ} \mathrm{C}$ & & \\
\hline Strain (4) & 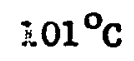 & & & & & & $35^{\circ} \mathrm{C}$ \\
\hline Chapter II & & $58^{\circ} \mathrm{C} / 4 \mathrm{~mm}$ & $\begin{array}{l}\mathrm{n}_{\mathrm{D}}^{20} \\
1.5259\end{array}$ & $\begin{array}{l}d^{20} \\
0.9799\end{array}$ & $203^{\circ} \mathrm{C}$ & $222^{\circ} \mathrm{C}$ & $35^{\circ} \mathrm{C}$ \\
\hline
\end{tabular}

Phenylacetaldimine and its Derivatives

Grignard and

Escourrou (6)

Chapter II $212-213^{\circ} \mathrm{C} / 750 \mathrm{~mm}$. $\mathfrak{n}_{\mathrm{p}}^{20}$

$\mathfrak{n}_{1}^{20}$
1.5402

$212^{\circ} \mathrm{C} / 731 \mathrm{~mm}$

$\mathrm{n}_{\mathrm{D}}^{20}$

1.5251

$180^{\circ} \mathrm{C}$

$173^{\circ} \mathrm{C}$

$153-4^{\circ} \mathrm{C}$ 
TABLE V (Continued)

Diphenylacetaldimine and 1ts. Derivatives

Kohler and 129d

Drake (9)

$120^{\circ} \mathrm{C}$

Chapter II

$*_{A}$ - Aldimine Hydrochloride

B - Semicarbazone of Aldimine Hydrolysis Product

C - Oxime of Aldimine Hydrolysis Product. 
TA_BLE VI

CAMPARISON OF ALDTMINE YIELDS OBTAINED

Substituted Alifhatic Imines

\begin{tabular}{llcl}
\hline \multicolumn{1}{c}{ Imines } & $\begin{array}{c}\text { Yield of } \\
\text { Complex }\end{array}$ & $\begin{array}{c}\text { Monomer } \\
\text { Yield }\end{array}$ & $\begin{array}{c}\text { Combined } \\
\text { Yield }^{3}\end{array}$ \\
\hline $\begin{array}{l}\text { Phenylacetaldimine } \\
\text { Diphenylacetaldimine }\end{array}$ & $79.8 \%$ & $70 \%$ \\
$\alpha$-ĩapithylacetaldimine & $1.3 \%$ & $23 \%$
\end{tabular}

Unsubstituted Benzaldimine

Imine

Benzaldimine

$90 \% \quad 93.9 \%$

Disubstituted Benzenoid Imines

Imines with Blectron

Donating Substituent

\begin{tabular}{|c|c|c|c|}
\hline o-Tolualdimine & $30 \%$ & $11.2 \%$ & $21.3 \%$ \\
\hline m-Tolualdimine & $98 \%$ & & $50 \%$ \\
\hline p-Tolualdimine & $70 \%$ & $25 \%$ & $70 \%$ \\
\hline \multicolumn{4}{|c|}{$\begin{array}{l}\text { Imines with Blectron } \\
\text { Withdrauing Substituent }\end{array}$} \\
\hline ouChl orobenzald Imine & $72.5 \%$ & $21.8 \%$ & \\
\hline p-Chlorobenzaldimine & $99 \%$ & $72 \%$ & \\
\hline \multicolumn{4}{|l|}{ p-Aldehydoienzaldinine } \\
\hline p-Aldiminobenzoic Acid & $95 \%$ & $26.2 \%$ & \\
\hline
\end{tabular}


TABLE VI (Continued)

o-Tr:Lchloromethylbenzaldimine

p-Trichl oromet hyllenzaldimine

Unsubstituted Naphthaldimine

Imine

$\alpha$-Naphthaldimine

$15.4 \%$

$49.5 \%$

1 - The waight of the precipitated intermediate was taken as pure complex for the yield calculation. The yield shown was not necessarily the percent of nitrile complex formed.

2 - This yield was calculated from the amount of nitrile used in the reaction

3 - The combined yield was calculated by taking the weight of polymer isolated as that of imine, and adding this to the amount of monomer isolated. 
CHAPTER V

\section{SIMPARY}

Although secondary fmines and substituted primary imines have been studied and characterized, very little attention has ever been paid to the unsubstituted terminal imines. These aldimines are considered to be intermediates in many organic reactions such as the Gattermann aldehyde synthesis and the reduction of nitriles, but, due to the difficulty of isolating them and, perhaps, lack of interest, only a very few of the compounds have been described. This important and relatively untouched field of aldimine preparation and characterization was chosen as the subject of this study.

The general approach to imine preparation was a modification of the Stephen aldehyde synthesis. This synthesis involves the formation of a stable, isolable intermediate complex from reaction of a nitrile with a diechyl ether solution of stannous halide which has been saturated with the corresponding hydrogen halide. This complex has the general form: ( $R-C H=N H \cdot E X)_{2} S_{n} X_{4}$. Decomposition of this intermediate under anhydrous conditions produces the corresponding aldimine. Attempts were made to prepare nineteen aldimines. In five of these cases attempts to prepare the stephen complex were unsuccess ful, although a complex of some kind was obtained each time. In all but two 
of the remaining fourteen preparatione fimine monomer was 1solated, and even in these cases a polymeric substance formed from the imine was obtained. The aldimines were characterized by determination of physical constants, analysis for nitrogen content and for total alkalinity, preparation of derivatives, and study of their infra-red spectra.

A number of compounds needed for the imine synthesis were also prepared. The methods of preparation are reported.

In addition to the preparative and identification work mentioned, a short study of the polymeric material formed by imines was made. It was found that hydrolysis of the polymers resulted in high yields of aldehydes corresponding to the monomeric imines. Unfortunately, all attempts to obtain the imine monomers from the polymeric substances were unsuccessful. Infra-red studies of polymer formation suggested that the polymers formed in the presence of heat were the same as those initiated by addition of free radicals and heat. The only difference seemed to be a faster polymerization rate in the latter case. Due to the almost complete lack of information on the chemical reactivity of aldimines, particularly their ability to form a variety of tin containing complexes and their tendency to polymerize, progress on this problem has not been rapid. Now that many of the difficulties in preparation and isolation have been solved, the way is open for some very interesting studies in the future. Among those which should be parifularly important and fruitful are comparisons of steric effects in influencing yield and compound stability, and studies of inductive effects on Imine reactivity. The author hopes that interest and work on these compounds does not end with this dissertation. 


\section{BIBLICGRAPHY}

(1) Ettling, E., Ann., 35, 256 (1840).

(2) Reychler, A., Ber., 17, 41 (1884).

(3) Delepine, A., Ann. Chim., [7], 16, 103 (1899).

(4) Strain, H. H., J. Am. Chem. Soc., 54 , 1221 (1932).

(5) Busch, H., Ber., 29, 2143 (1896).

(6) Grignard, V. and Escourrou, R., Compt. rend., 180, 1883 (1925).

(7) Bscourrou, R., Bul1. soc. ch1m. France, 45, 735 (1929).

(8) Strain, H. H., J. Am. Chem. Soc., 49, 1558 (1927).

(9) Kohlar, B. P. and Drake, N. L., J. Am. Chem. Soc, , 45, 1281 (1923).

(10) Gravin, A. I., J. Appl. Chem. U.S.S.R., 16, 105 (1943) C. A., 38, 1239 (1944).

(11) Stephen, H., J. Chem. Soc., 1925, 1874.

(12) Lieber, B., J. Am. Chem. Soc., 71, 2862 (1941).

(13) Knight, J. A. and Zook, H. 0., J. Am. Chem. Soc., 74, 4560 (1952).

(14) Turner, L., J. Chem. Soc., 1956, 1686.

(15) Bayer, B., Hethoden der organischen Chemie (Houben-Weyl), G. Thieme, Stuttgart, 1954, 4th Ed., Vol. VII, Pt. 1.

(16) Wittig, G. and Hartmann, H., Ber., 72B, 1387 (1939).

(17) Slotta, K. H. and Kether, R., Ber., 71, 335 (1938).

(18) Mosettig, E., Organic Raactions, J. Wiley and Sons, Inc., New York, 1954, Vol. VIII, p. 246.

(19) Stephen, T. and Stephen, H., J. Chem. Soc., 1956, 4695. 
(20) Work, T. S., J. Chem. Soc., 1946, 197.

(21) Williams, J. W., J. Am. Chem. Soc., ói, 2248 (1939).

(22) KIng, F. B., Liguori, M. and Robinson, R., J. Chem. Soc., 1933, 270.

(23) King, F. B. and Robinson, R., J. Chem. Soc., 1933, 1475.

(24) King, F. B., L'Ecuyer, P. and Openshaw, H. T., J. Chem. Soc., $\underline{1936}, 352$.

(25) King, F. E., Clifton, J. W. and Openshaw, H. T., J. Chem. Soc., 1942,422 .

(26) Reissert, A., Ber., 38, 1603 (1905).

(27) Witt1g, G., Kethur, B., Kle1n, A. and Wietbrock, R., Ber., 69B, 2078 (1936).

(28) McElvain, S. M. and Clarke, R. L., J. Am. Chøm. Soc., 69, 2657 (1947).

(29) Fulton, J. D. and Robinson, R., J. Chem. Scc., 1939, 200.

(30) Wood, J. H. and Stanifield, J. A., J. Am. Chem. Soc., 64, 2343 (1942).

(31) Bowen, J. B. and Wilkenson, B. M., J. Chem. Soc., 1950, 750.

(32) Brown, J. H., Suckling, C. W. and Whalley, W. B., J. Shem. Soc, 1943, S35.

(33) Bernstein, J., Yale, H. L., Losee, K., Holsing, M., Martins, J. and Lott, W. A., J. Am. Chem. Soc., 73, 906 (1951).

(34) English, J., Mead, J. F. snd Niemann, C., J. Am. Chem. Soc, , 62, 350 (1940).

(35) Gray, R. and Bonnar, J., J. Am. Chem. Soc., 70, 1249 (1948).

(36) Baker, W. and Robinson, R., J. Chem. Soc., 1929, 152.

(37) Block, P. and Powell, G., J. Am. Chem. Soc., 64, 1070 (1942).

(38) Niemann, C. and Mead, J. F., J. Am. Chem. Soc., 63, 2685 (1941).

(39) Niemann, C. and Redemann, C. E., J. Am. Chem. Soc., 63, 1549 (1941). 
(40) Schuegraf, K., Helv. ChIm. Acta, 12, 405 (1929).

(41) Harington, C. R. and Borger, G., Blochem. J., 21, 169 (1927).

(42) Niemann, C., Moad, J. F. and Benson, A. A., J. Am. Chem. Soc., 63, 609 (1941).

(43) Burton, H. and Hu, P. F., J. Chem. Soc., 1948, 601.

(44) Law, G. E. and Johnson, T. B., J. Am. Chem. Soc., 52, 3623 (1930).

(45) Harington, C. R., Biochem. J., 43, 434 (1948),

(46) de Klewlet, T. Z. and Stephen, H., J. Clsem. Soc., 1931, 84.

(47) Cornforth, J. W., Fawaz, E., Coldsworthy, L. J. and Robinson, R., J. Chem. Soc., 1949, 1549 .

(48) Harington, C. R. and Moggridge, R. C. G., J. Chem. Soc., 1939, 433.

(49) Stephen, H., J. Chen. Soc., 1930, 2786.

(50) Miller, C. S., Organic Syntheses, J. Wiley and Sons, Inc., New York, 1955, Coll. Vol. III, p. 646.

(51) Storrie, F. R., J. Chem. Soc., 1937, 1746.

(52) Valky, E. P. and Lucas, H. J., J. Am. Chem. Soc., 51, 2718 (1929).

(53) Hass, H. B. and Bender, M. L., J. Am. Chem. Soc., 71, 1767 (1949).

(54) Beckmann, B., Ber., 26, 2621 (1853).

(55) Fock, A., Ber. 20, 3198 (1887).

(56) Yagupol'skii, L. M. and Man'ko, N. I., Zhur. Obshchei Khim., 23, 988 (1953)

C. A., 48,8194 (1954).

(57) Engles, E. F., Ph.D. Dissertation, University of Oklahoma, 1951 Plckard, P. L. and Engles, B. F., J. Am. Chem. Soc., 73, 864 (1951).

(58) Iddings, F. A., Unpublished M. S. Thesis, Department of Chemistry, University of Oklahoma, 1956.

(59) Glasstone, S., Textbook of Physical Chemistry, D. Van Nostrand Co., New York, 1946, 2nd Bdition. 
(60) Shriner, R. L., Fuson, R. C. and Curtin, D. Y., The Systematic Identification of Organic Compounds, J. Wiley and Sons, Inc., New York, 1956, 4th Edition.

(61) Plckard, P. L. and Polly, G., J. Am. Chem. Soc., 76, 516. (1954).

(62) Scott, W. W., Standard Methods of Chemical Analysis, D. Van Nostrand Co., Now York, 1939, Vol. II, p. 956.

(63) Sand, H. J. S., Blectrochemietry and Blectrochemical Analysis, Blackle and Son, Ltd., Glasgow, 1940, Vol. II, p. 70.

(64) Fuson, R. C., J. Am. Chem. Soc., 48, 830 (1926).

(65) Ralford, L. C. and Clark, E. P., J. Am. Chem. Soc., 45, 1738 (1923). 